\title{
The Macroeconomic Effects of Quantitative Easing in the Euro Area: Evidence from an Estimated DSGE Model
}

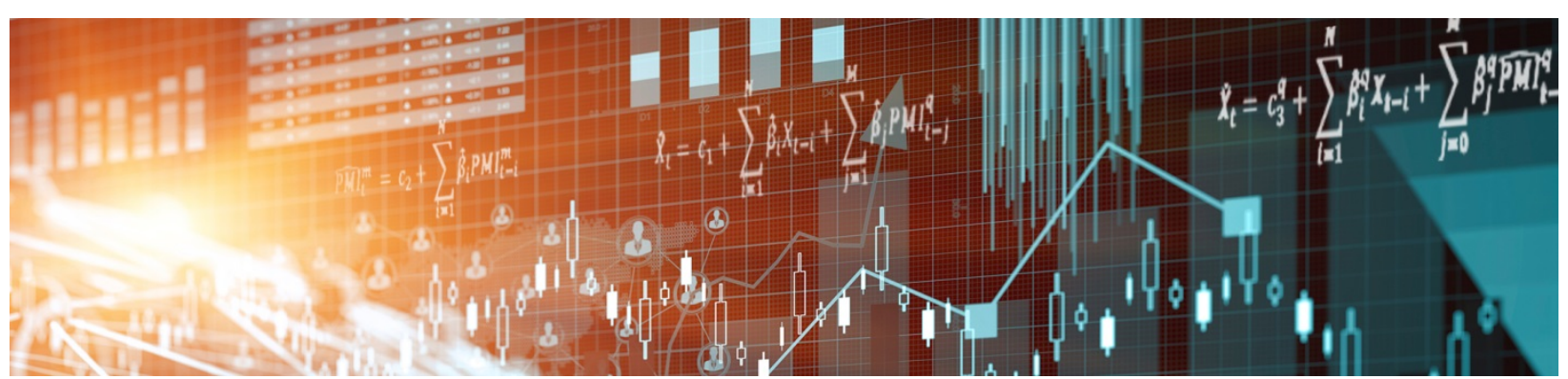

by Stefan Hohberger, Romanos Priftis and Lukas Vogel 
Bank of Canada Staff Working Paper 2018-11

March 2018

\title{
The Macroeconomic Effects of Quantitative Easing in the Euro Area: Evidence from an Estimated DSGE Model
}

\author{
by \\ Stefan Hohberger, ${ }^{1}$ Romanos Priftis ${ }^{2}$ and Lukas Vogel ${ }^{3}$ \\ 1 European Commission \\ Ispra, Italy \\ Stefan.hohberger@ec.europa.eu \\ 2 Canadian Economic Analysis Department \\ Bank of Canada \\ Ottawa, Ontario, Canada K1A OG9 \\ rpriftis@bankofcanada.ca \\ ${ }^{3}$ European Commission \\ Brussels, Belgium \\ Lukas.vogel@ec.europa.eu
}




\section{Acknowledgements}

We thank Jean-Philippe Cayen, Julien Champagne, Fabian Eser, Stefano Gnocchi, Massimo Giovannini, Richard Harrison, Serdar Kabaca, Beatrice Pataracchia, Marco Ratto and Werner Roeger for very helpful suggestions and discussions, and seminar participants at the Bank of Canada, the 14th Annual EEFS Conference, the 47th MMF Research Group Annual Conference, the 6th IWH/INFER Workshop on (Ending) Unconventional Monetary, the 1st CEPR Conference on Macro-Modelling and Model Comparison, the 21st International Conference on Macroeconomic Analysis and International Finance, the 2017 Annual Meeting of the German Economic Association, the 2017 European Winter Meeting of the Econometric Society, and XENOPHON 2017 for helpful comments on this and previous versions of the paper. The views expressed are those of the authors and should not be attributed to the Bank of Canada or the European Commission. 


\begin{abstract}
This paper estimates an open-economy dynamic stochastic general equilibrium model with Bayesian techniques to analyse the macroeconomic effects of the European Central Bank's (ECB's) quantitative easing (QE) programme. Using data on government debt stocks and yields across maturities, we identify the parameter governing portfolio adjustment in the private sector. Shock decompositions suggest a positive contribution of ECB QE to annual euro area output growth and inflation in 2015-16 of up to 0.3 and 0.6 percentage points (pp) in the linearised version of the model. Allowing for an occasionally binding zerobound constraint by using piecewise linear solution techniques raises the positive impact to up to 0.7 and $0.8 \mathrm{pp}$.
\end{abstract}

Bank topics: Economic models; Interest rates; Transmission of monetary policy JEL codes: E44, E52, E53, F41

\title{
Résumé
}

Nous estimons, par des techniques bayésiennes, un modèle d'équilibre général dynamique et stochastique en économie ouverte afin d'analyser les effets macroéconomiques du programme d'assouplissement quantitatif de la Banque centrale européenne (BCE). À partir des données portant sur l'encours des titres d'État et les taux de rendement pour la gamme des échéances, nous évaluons le paramètre qui détermine les ajustements de portefeuilles dans le secteur privé. Les décompositions de chocs effectuées montrent qu'en zone euro, les mesures d'assouplissement quantitatif de la BCE auraient entraîné, en 20152016, des effets positifs sur la croissance annuelle de la production et sur l'inflation à hauteur de 0,3 et 0,6 point de pourcentage dans la version linéarisée du modèle. Lorsque nous permettons que la contrainte de la borne du zéro soit occasionnellement active au moyen de techniques de linéarisation, l'incidence favorable se chiffre respectivement à 0,7 et 0,8 point de pourcentage.

Sujets : Modèles économiques; Taux d'intérêt; Transmission de la politique monétaire Codes JEL : E44, E52, E53, F41 


\section{Non-technical Summary}

In early 2015 the European Central Bank (ECB) joined the group of central banks that have implemented large-scale asset purchase programmes as unconventional policy measures. The ECB's quantitative easing (QE) programme, announced in January 2015, foresaw buying $€ 60$ billion of assets a month from March 2015 to September 2016, which in sum corresponds to circa 10\% of annualised euro area (EA) gross domestic product (GDP). It has been continuously revised in both size and duration since then.

This paper analyses the macroeconomic effects of the ECB's QE programme using a tworegion dynamic stochastic general equilibrium (DSGE) model for the EA and the rest of the world, estimated with Bayesian techniques. The estimation of the model is undertaken in an environment where the zero lower bound may be binding and to solve such models requires extending previous algorithms. QE is introduced into the model by adding a central bank balance sheet and distinguishing between short-term and long-term government debt. We use a formulation of a private-sector portfolio that allows for non-neutral effects of central bank purchase programmes due to imperfect substitutability between assets of different maturity. The central bank alters its balance sheet by purchasing long-term bonds and injecting liquidity to the private sector. When the central bank intervenes, private investors that aim at re-establishing the portfolio mix of shortterm and long-term assets can respond by holding more corporate equity and foreign bonds, and by reducing savings. The first response means a portfolio reallocation towards equity and foreign-currency assets that increases the price of corporate equity (rising stock market) and the price of foreign currency (exchange rate devaluation). The second response implies a substitution away from future consumption.

Combining data on government debt stocks and yields across maturities, the model estimation provides a value for the parameter governing portfolio adjustment costs in the model. The implied magnitude of these costs determines the yield spread following QE of a given volume and time path, such as the one announced by the ECB in January 2015. Our results show that QE as captured by the model has increased EA year-on-year output growth and inflation in 2015q1$17 \mathrm{q} 1$ by 0.7 percentage points (pp) and $0.8 \mathrm{pp}$ on average, with maximum impact at $1.0 \mathrm{pp}$ in $2016 \mathrm{q} 1$ and 2017q1. Our estimated DSGE model can also reproduce the narrative of the pre-QE growth slowdown in the EA and, in particular, during the Great Recession. 


\section{Introduction}

In early 2015 the European Central Bank (ECB) joined the group of central banks that have implemented large-scale asset purchase programmes as unconventional policy measures. These asset purchases, also called quantitative easing $(\mathrm{QE})$, have led to a strong extension of the central banks' balance sheets. By end-July 2015 the amount of outright purchases on the balance sheet had reached $24 \%$ of gross domestic product (GDP) in the case of the US Federal Reserve, $64 \%$ of GDP in the case of the Bank of Japan, 21\% of GDP in the case of the Bank of England, and 5\% of GDP in the case of the ECB (Constâncio 2015). The ECB's QE programme, announced in January 2015 (Public Sector Purchase Programme), foresaw buying €60 billion of assets a month from March 2015 to September 2016, which in sum corresponds to circa 10\% of annualised euro area (EA) GDP. In December 2015, the ECB extended the programme until March 2017, and it raised the amount of monthly purchases to $€ 80$ billion starting from April 2016. In December 2016 the programme was extended and modified again, lengthening the period of asset purchases until (at least) December 2017, but at a reduced pace of $€ 60$ billion of assets a month after March 2017.

Operating close to the zero lower bound (ZLB), the ECB considered its "conventional" monetary accommodation to be insufficient to address weak inflation dynamics, falling inflation expectations and sizeable economic slack in the EA. As a result, the balance sheet interventions were proposed to "achieve the price stability objective, given that interest rates have reached their lower bound" (Draghi 2015). In practice, the ECB purchases public sector financial assets (government debt) of longer maturity and extends liquidity (base money) to the private sector. Research at the ECB has provided evidence for the impact of the QE programme on long-term bond yields and spillover to other asset prices through portfolio reallocation: Altavilla et al. (2015) in an event study report a 30-50 basis-point decline in 10-year government bond yields with spillover into lower corporate bond, spreads, higher equity prices, and euro depreciation. Andrade et al. (2016) report a decline of EA 10-year government bond yields in the range of 27-64 basis points in the context of the ECB's extended asset purchases programme with spillover into higher equity prices and inflation expectations. The evidence in De Santis (2016) suggests that ECB non-standard policy has reduced EA 10-year government bond yields between September 2014 and October 2015 on average by 63 basis points.

This paper analyses the macroeconomic effects of the ECB's QE programme using a tworegion dynamic stochastic general equilibrium (DSGE) model for the EA and the rest of the world (RoW), estimated with Bayesian techniques. QE is introduced into the model by adding a 
central bank balance sheet and distinguishing between short-term and long-term government debt. We use a formulation of private-sector portfolio preferences that is by now established in the literature (e.g., Andrés et al. 2004, Priftis and Vogel 2016) and that allows for non-neutral effects of central bank purchase programmes due to imperfect substitutability between assets of different maturity. More specifically, the central bank alters its balance sheet by purchasing longterm bonds (the latter modelled as in Woodford 2001) and injecting liquidity into the private sector. Our specification of QE allows us to capture its effects through a large number of the transmission channels put forward by the literature (see Krishnamurthy and Vissing-Jorgensen 2011) including the saving, financing cost, exchange rate, inflation, and fiscal channels. The movement of the exchange rate in response to $\mathrm{QE}$ affects aggregate demand, output and inflation and is a channel that is absent from most model-based studies of QE policies (e.g., Chen et al. 2012, De Graeve and Theodoridis 2016, Gertler and Karadi 2013) which, instead, build on closed-economy frameworks. Since our framework relies on a global two-region model, we explicitly account for effects that arise from exchange rate adjustment and the behaviour of net exports.

The contribution of this paper is to analyse the macroeconomic impact of ECB QE using a state-of-the-art estimated DSGE model. We first show that our model can reproduce the narrative of the pre-QE growth slowdown in the EA and, in particular, during the Great Recession. We then focus on the ECB's QE programme. Combining data on government debt stocks and yields across maturities, the model estimation provides a value for the parameter governing the portfolio adjustment costs in the model. The implied magnitude of these costs determines the yield spread following QE of a given volume and time path, such as the one announced by the ECB in January 2015. Given that ECB QE was launched only in 2015, we have few data points for the QE episode itself. Data-driven identification of the degree of substitutability between short-term and long-term bonds in our model therefore has to rely mainly on the pre-QE part of the sample. Lags in the transmission of QE to the real economy furthermore imply that the effects of the ongoing programme have not fully materialised yet.

The analysis starts with a standard linearised version of the model in which the Taylor rule never hits the ZLB (we refer to this as the "unconstrained model" in the text). We then turn to a model version with occasionally binding constraints in which the ZLB can become binding endogenously when contractionary shocks drive the target ("shadow") interest rate below the lower bound (we refer to this as the "constrained model" in the text). According to our shock decompositions from the estimated unconstrained model, QE as captured by the model has increased EA year-on-year output growth and inflation in $2015 q 1-17 q 1$ by 0.3 percentage points (pp) and $0.5 \mathrm{pp}$ on average, with maximum impact of $0.4 \mathrm{pp}$ and $0.6 \mathrm{pp}$ in 2016. Including the 
endogenously and occasionally binding ZLB constraint raises the 2015q1-17q1 average growth and inflation effect of QE to $0.7 \mathrm{pp}$ and $0.8 \mathrm{pp}$, respectively, with peaks at $1.0 \mathrm{pp}$ in $2016 \mathrm{q} 1$ and 2017q1, respectively. The stronger QE impact in the constrained model is due to the absence of a countervailing short-term policy rate response when the ZLB binds in 2015-16 in the constrained model.

The remainder of the paper is structured as follows: Section 2 summarises the closely related literature; section 3 outlines the general structure of the model; section 4 describes the model solution and estimation methodology; section 5 presents parameter estimates; section 6 discusses the impact of QE in the unconstrained model; section 7 presents results from the model with the occasionally binding constraint; section 8 summarises the paper and concludes. A full model description is provided in the online appendix.

\section{Related Literature}

The empirical relevance of individual channels and the aggregate macroeconomic effects of QE are an empirical matter and likely to vary with structural features of the economy across countries and time. So far there is little (published) research on the effects of the ECB QE and, particularly, little model-based analysis. Most existing papers consider unconventional monetary policy in the US and the UK and their spillovers to the world economy. This literature has been summarised, e.g., in Priftis and Vogel (2016). Here, we limit ourselves to the review of model-based generalequilibrium (DSGE) analyses that focus on the impact of QE on portfolio rebalancing and financing costs.

The central contribution of this paper is the incorporation of central bank balance sheet policy (QE) in a large-scale open-economy macroeconomic model and estimation of this model on EA data. The approach is similar in spirit to Chen et al. (2012), and De Graeve and Theodoridis (2016) who analyse US QE in estimated closed-economy models of the US economy. In line with Chen et al. (2012), De Graeve and Theodoridis (2016), and Harrison (2017), we focus on the portfolio balancing channel of QE transmission.

According to the results in Chen et al. (2012), the US large-scale asset purchase (LSAP II) programme, with a volume of circa $4 \%$ of US GDP, combined with a commitment to keep interest rates low for an extended period of time, has raised US real GDP growth by around $0.13 \%$ and inflation by only $0.03 \mathrm{pp}$. According to the estimates of De Graeve and Theodoridis (2016), "Operation Twist", the purchase of long-term and sale of short-term maturity bonds of circa $2 \%$ of US GDP by the Federal Reserve, has increased US real GDP by $0.6 \%$ and inflation by up to 
$0.3 \mathrm{pp}$.

The models by Gertler and Karadi (2013) and Carlstrom et al. (2017) assume financially constrained financial intermediaries, where QE eases the constraint on financing productive investment in the economy. In these models, productive capital is financed by financial intermediaries based on their net worth and the deposits made by households. In a calibrated version of their model, Gertler and Karadi (2013) quantify the impact of US LSAP with a volume of 2.5\% of GDP on output and inflation to $1 \%$ and $1.5 \mathrm{pp}$, respectively, if policy rates remain unchanged, and to $0.2 \%$ and $0.2 \mathrm{pp}$, respectively, if the standard monetary policy rule is active and partly offsets expansionary QE effects by an increase in the short-term rate. While the transmission can be described in terms of the credit channel, recent empirical analyses (see, e.g., Bluwstein and Canova 2016) do not suggest that the credit channel is a primary transmission mechanism for QE in the EA and spillover to non-EA countries.

Sahuc (2016) borrows the Gertler-Karadi model for an assessment of ECB QE policy that involves asset purchases of circa 9\% of EA GDP. Like Gertler and Karadi (2013), the Sahuc (2016) assessment stresses the importance of keeping short-run policy rates low for longer. Keeping the policy rate constant only in 2015 gives a maximum QE effect on output growth and inflation of 0.2 and $0.1 \mathrm{pp}$ in 2015-16, whereas keeping the policy rate unchanged for another year raises the average output growth and inflation effect in 2015-16 to 0.6 and 0.6 pp.

\section{Model Description}

The present analysis uses a modified two-region (EA and RoW) framework of Kollmann et al. (2016) and extends this model to incorporate non-standard monetary policy. The model is estimated using quarterly data for the period 1999q1-2017q1.

The EA region assumes two (representative) households, intermediate and final goods firms and a government. Ricardian households have access to financial markets, whereas liquidity-constrained households consume their disposable income in every period. Preferences of both types of households exhibit habit formation in both consumption and leisure. A monopolistically competitive sector produces differentiated goods by employing domestic labour and capital. Firms in this sector maximise the present value of their dividends at a discount factor that is strictly larger than the risk-free rate and varies over time, subject to investment and labour adjustment costs and a varying capacity utilisation rate. Final goods firms combine a domestic differentiated goods bundle with energy inputs. Nominal differentiated goods prices are sticky, as 
are the wages paid to the workers - the latter being determined by monopolistic trade unions. The fiscal authority imposes distortive taxes and issues debt.

The exposition below describes the QE-relevant extensions. A detailed overview of the general model can be found in Kollmann et al. (2016) and in the online appendix. We extend the model by introducing non-standard monetary policy as in Priftis and Vogel (2016). Our approach is similar to the modelling of QE in Chen et al. (2012), and De Graeve and Theodoridis (2016), which focuses on the portfolio rebalancing in the transmission of QE. However, unlike these studies, our two-region model allows for an exchange rate channel of QE and trade effects.

In line with the standard notion, QE is introduced as a monetary policy strategy that increases the size of the central bank's balance sheet. In particular, the central bank purchases longterm (government) bonds, with the aim of reducing the interest spread between long and short maturities; i.e., to flatten the yield curve. The central bank finances the bond purchases by providing additional liquidity to the private sector. QE intends to affect private-sector portfolio and saving decisions, especially when short-term policy rates are already at or close to the ZLB.

We introduce short-term and long-term government debt to incorporate investor preferences for a maturity mix and central bank balance sheet operations in the model. Following Woodford (2001), long-term government debt is modelled through bonds for which the nominal coupon $c$, which is a fraction of the principal, depreciates over time at rate $\delta_{b}{ }^{5}$ The price in period $t$ of a long-term bond issued in $t\left(P_{t}^{N}\right)$ equals the discounted value of future payments $P_{t}^{N}=\sum_{n=0}^{T} \frac{\delta_{b}^{n}}{(1+i)^{1+n}} c$, where $\mathrm{T}$ is the maturity period of the bond. Analogously, the price in period $t$ of a long-term bond issued in $t-1\left(P_{t}^{o}\right)$ equals the discounted sum of outstanding payments, $P_{t}^{o}=\sum_{n=0}^{T-1} \frac{\delta_{b}^{1+n}}{(1+i)^{1+n}} c$. If $\delta_{b} /(1+i)<1$ and $T$ is large, the price in $t$ of long-term bonds issued in $t-1$ corresponds (approximately) to the price of newly issued long-term bonds times the depreciation rate:

(1) $P_{t}^{o}=\delta_{b} P_{t}^{N}$

Equation (1) shows that the price of the long-term bond that pays a declining coupon declines over time at the rate $\delta_{b}$. Total outstanding government debt at face value consists of long-term bonds $B_{t}^{L}$, held by the private sector $\left(B_{t}^{L, H}\right)$ and the central bank $\left(B_{t}^{L, C B}\right)$, and short-term bonds, $B_{t}^{s}:$

\footnotetext{
${ }^{5}$ The Woodford (2001) perpetual-bond formulation is also be used by, e.g., Carlstrom et al. (2017).
} 


$$
B_{t}=B_{t}^{L, H}+B_{t}^{L, C B}+B_{t}^{S}
$$

The short-term and long-term bonds are imperfect substitutes in the model. In particular, private investors have a preference for holding a mix of short-term and long-term bonds, and deviations from the target value $\kappa$ for the ratio of long-term over short-term debt induce quadratic adjustment costs $\left(\gamma_{b}\right){ }^{6}$

Private households with access to financial markets (superscript $r$ for Ricardian) face the following optimisation problem: ${ }^{7}$

$$
\begin{aligned}
& \max L^{r}=\mathrm{E}_{0} \sum_{t=0}^{\infty} \beta^{t} U\left(C_{t}^{r}, 1-N_{t}^{r}\right)
\end{aligned}
$$

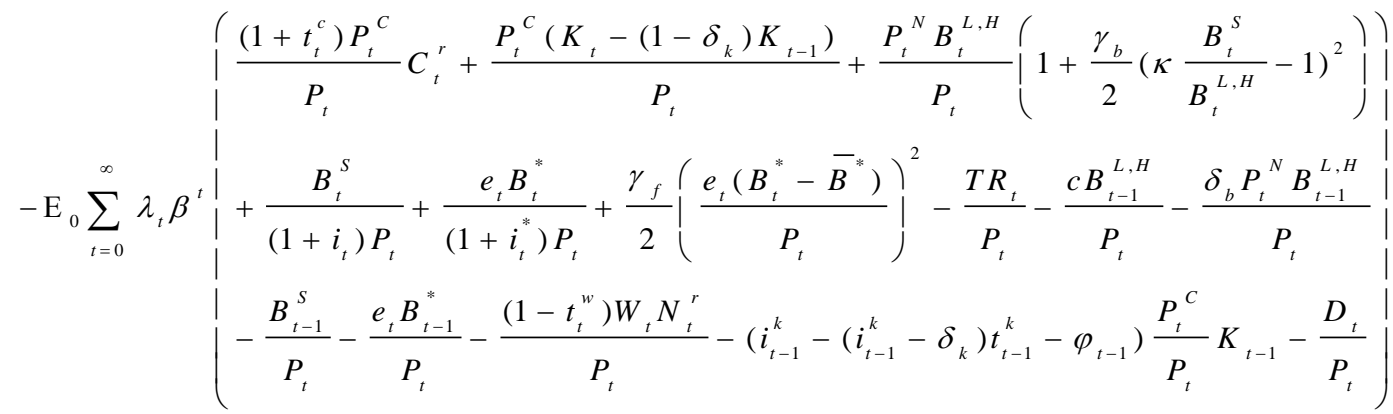

Ricardian households receive labour income, returns on financial assets, income $i_{t}^{k}$ from lending capital to firms net of an (exogenous) risk/insurance premium given revenue uncertainty $\varphi_{t}$, and dividends $D_{t}$ from firm ownership. $K_{t}=I_{t}+\left(1-\delta_{k}\right) K_{t-1}$ is the capital stock as the sum of new investment $I_{t}$ and the pre-period capital stock depreciated at rate $\delta_{k}$. The government levies taxes $t_{t}^{w}$ on income from labour, $t_{t}^{k}$ on corporate income and $t_{t}^{c}$ on consumption. The price in period $t$ of a short-term (1-period) bond of nominal value $B_{t}^{S}$ is $B_{t}^{s} /\left(1+i_{t}\right)$, with $i_{t}$ being the short-term nominal interest rate. Analogously, $e_{t} B_{t}^{*} /\left(1+i_{t}^{*}\right)$ is the price in domestic currency of a foreign bond $B_{t}^{*}$, where $e_{t}$ is the nominal exchange rate as the value in domestic currency of one unit of foreign currency.

The maximisation problem (3) provides the following first-order conditions (FOC):

$$
\frac{\partial L^{r}}{\partial B_{t}^{S}} \Rightarrow \beta E_{t}\left(\frac{\lambda_{t+1}}{\lambda_{t}}\right)=E_{t}\left(\frac{P_{t+1}}{P_{t}}\right)\left(\frac{1}{1+i_{t}}+\gamma_{b} \kappa P_{t}^{N}\left(\kappa \frac{B_{t}^{S}}{B_{t}^{L, H}}-1\right)\right)
$$

\footnotetext{
${ }^{6}$ The same formulation has been used previously by, e.g., Andrés et al. (2004), Falagiarda (2013), Harrison (2017), and Liu et al. (2015).

${ }^{7}$ The description of the budget constraint here omits adjustment costs in the real sector of the economy (price, wage, capital stock, and labour adjustment costs) that do not affect the first-order conditions for portfolio holdings and savings. These adjustment costs (which generate, e.g., nominal price and wage stickiness) are present in the full version of the model that underlies the simulations. Details on the specification of the real-sector adjustment frictions can be found in e.g., Priftis and Vogel (2016) and the online appendix.
} 


$$
\frac{\partial L^{r}}{\partial B_{t}^{L, H}} \Rightarrow \beta E_{t}\left(\frac{\lambda_{t+1}}{\lambda_{t}}\right)=E_{t}\left(\frac{P_{t}^{N}}{\delta_{b} P_{t+1}^{N}+c} \frac{P_{t+1}}{P_{t}}\right)\left(1+\frac{\gamma_{b}}{2}\left(\kappa \frac{B_{t}^{S}}{B_{t}^{L, H}}-1\right)^{2}-\gamma_{b} \kappa\left(\kappa \frac{B_{t}^{S}}{B_{t}^{L, H}}-1\right) \frac{B_{t}^{S}}{B_{t}^{L, H}}\right)
$$

$$
\frac{\partial L^{r}}{\partial B_{t}^{*}} \Rightarrow \beta E_{t}\left(\frac{\lambda_{t+1}}{\lambda_{t}}\right)=E_{t}\left(\frac{e_{t}}{e_{t+1}} \frac{P_{t+1}}{P_{t}}\right)\left(\frac{1}{1+i_{t}^{*}}+\gamma_{f} \frac{e_{t}\left(B_{t}^{*}-\bar{B}^{*}\right)}{P_{t}}\right)
$$

$$
\begin{aligned}
& \frac{\partial L^{r}}{\partial K_{t}} \Rightarrow \beta E_{t}\left(\frac{\lambda_{t+1}}{\lambda_{t}}\right)=E_{t}\left(\frac{P_{t+1}}{P_{t}} \frac{P_{t}^{C}}{P_{t+1}^{C}}\right) \frac{1}{\left(1+i_{t}^{k}-\varphi_{t}-\delta_{k}\right)-t_{t}^{k}\left(i_{t}^{k}-\delta_{k}\right)} \\
& \frac{\partial L^{r}}{\partial C_{t}^{r}} \Rightarrow U_{t}^{C}=\frac{\left(1+t_{t}^{c}\right) P_{t}^{c}}{P_{t}} \lambda_{t} \\
& \frac{\partial L^{r}}{\partial N_{t}^{r}} \Rightarrow U_{t}^{N}=\frac{\left(1-t_{t}^{w}\right) W_{t}}{P_{t}} \lambda_{t}
\end{aligned}
$$

Combining (4) with (6), (7) and (8) illustrates the transmission channels of QE to the real economy:

$$
\begin{aligned}
& \frac{1}{1+i_{t}}+\gamma_{b} \kappa P_{t}^{N}\left(\kappa \frac{B_{t}^{S}}{B_{t}^{L, H}}-1\right)=E_{t}\left(\frac{e_{t}}{e_{t+1}}\right)\left(\frac{1}{1+i_{t}^{*}}+\gamma_{f} \frac{e_{t}\left(B_{t}^{*}-\bar{B}^{*}\right)}{P_{t}}\right) \\
& \frac{1}{1+i_{t}}+\gamma_{b} \kappa P_{t}^{N}\left(\kappa \frac{B_{t}^{S}}{B_{t}^{L, H}}-1\right)=E_{t}\left(\frac{P_{t}^{C}}{P_{t+1}^{C}}\right) \frac{1}{\left(1+i_{t}^{k}-\varphi_{t}-\delta_{k}\right)-t_{t}^{k}\left(i_{t}^{k}-\delta_{k}\right)} \\
& \frac{1}{1+i_{t}}+\gamma_{b} \kappa P_{t}^{N}\left(\kappa \frac{B_{t}^{S}}{B_{t}^{L, H}}-1\right)=\beta \frac{\left(1+t_{t}^{c}\right) P_{t}^{c} U_{t+1}^{C}}{\left(1+t_{t+1}^{c}\right) P_{t+1}^{c} U_{t}^{C}}
\end{aligned}
$$

The impact on asset prices of the central bank's purchase of long-term bonds derives from the private investors' portfolio adjustment $\operatorname{costs}\left(\gamma_{b}>0\right)$, i.e., imperfect substitutability between different financial assets. If $\gamma_{b}>0$, the effects of reducing $B_{t}^{L, H}$ relative to $B_{t}^{S}$ in the household portfolio are similar to the impact of a reduction of the short-term interest rate $i_{t}$ in equation (4), and unconventional monetary policy can, hence, mimic the effect of reductions in the short-term interest rate.

In particular, when the central bank intervenes by purchasing long-term bonds, private investors that aim at re-establishing the portfolio mix of short-term and long-term assets can respond by holding more corporate equity and foreign bonds, and by reducing savings. The first response means a portfolio reallocation towards equity and foreign-currency assets that increases the price of corporate equity (rising stock market) and the price of foreign currency (exchange rate devaluation). Equation (10) shows that QE leads to higher demand for foreign assets and depreciation of the domestic currency (increase in $e_{t}$ ) for given levels of $i_{t}$ (restricted, e.g., at the ZLB) and $i_{t}{ }^{*}$. Equation (11) illustrates the portfolio reallocation from government bonds towards 
corporate equity. Equation (12) shows that QE reduces private saving similar to a reduction in the short-term interest rate.

Concerning the transmission to the real economy, i) rising stock markets reduce the financing costs of corporations and, dampening the required return to capital, translate - under decreasing returns to capital — into stronger investment and capital accumulation, ii) exchange rate depreciation strengthens net exports, provided that export and import demand are sufficiently price elastic, and iii) reduced savings to restore the preferred portfolio mix strengthen contemporaneous consumption demand.

The stock of government debt, which is composed of short-term bonds and long-term bonds follows:

$$
\frac{B_{t}^{S}}{\left(1+i_{t}\right) P_{t}}+\frac{P_{t}^{N}}{P_{t}} B_{t}^{L}=\frac{B_{t-1}^{S}}{P_{t}}+\frac{\left(\delta_{b} P_{t}^{N}+c\right) B_{t-1}^{L}}{P_{t}}+\frac{P G E_{t}}{P_{t}}-\frac{T A X_{t}}{P_{t}}-\frac{P R_{t}^{C B}}{P_{t}}
$$

where $P G E_{t}, T A X_{t}$ and $P R_{t}^{C B}$ are, respectively, the primary government expenditure (public consumption, public investment, transfers), total tax revenue (labour, consumption, and corporate taxes), and the operating profit of the central bank as an additional source of government revenue. The operating profit of the central bank equals the sum of base money issuance and interest income minus the current expenditure on buying long-term bonds, where the latter equals the change of the value of long-term bonds on the central bank's balance sheet:

$$
P R_{t}^{C B}=\Delta M_{t}+c B_{t-1}^{L, C B}-\left(P_{t}^{N} B_{t}^{L, C B}-\delta_{b} P_{t}^{N} B_{t-1}^{L, C B}\right)
$$

Under the central bank's budget constraint (14), purchases of long-term government bonds can be financed either by increasing liquidity (money issuance), or by reducing the central bank's operating profit. ${ }^{8}$ In line with the standard definition of QE and the ECB announcement, we consider only the case of enhanced liquidity provision.

Purchases of long-term bonds by the central bank can be modelled as an endogenous response to the economic environment (e.g., the economy's position in the business cycle, or the slope of the yield curve) similar to a Taylor rule, or as an exogenous path. We use the volume of the ECB's asset purchases as observable data and treat it as an exogenous path that replicates the announced ECB programme in timing and size.

\footnotetext{
${ }^{8}$ A third option, in general, is for the central bank to sell other assets from its portfolio to sterilise the impact of its intervention on the central bank balance sheet.
} 


\section{Model Solution and Econometric Approach}

We compute an approximate model solution by linearising the model around its deterministic steady state. Following the recent literature that estimates DSGE models, we calibrate a subset of parameters to match long-run data properties, and we estimate the remaining parameters using Bayesian methods. The observables employed in the estimation are listed in the data appendix. The estimation uses quarterly data for the period 1999q1-2017q1. The model has been estimated using the slice sampler algorithm proposed by Neal (2003). ${ }^{9}$

We calibrate the model steady state so that steady-state ratios of main economic aggregates to GDP match average historical ratios over the sample period. The EA steady-state ratios of private consumption and investment to GDP are set to $56 \%$ and $19 \%$, respectively. The steadystate share of EA GDP in world GDP is $17 \%$. The steady-state trade share $(0.5 *$ (exports + imports)/GDP) is set at $18 \%$ in the EA (excluding intra-EA trade), and the quarterly depreciation rate of capital is $1.4 \%$. We set the steady-state government debt/annual GDP ratio at $80 \%$ of GDP in the EA. The steady-state real GDP growth and inflation rates are set to $0.35 \%$ and $0.4 \%$ per quarter, respectively, and the effective rate of time preferences to $0.25 \%$ per quarter.

Regarding the model extension to non-standard monetary policy and imperfect asset substitutability, we observe three QE-specific series, namely (i) "securities held for monetary policy purposes" as proxy for long-term bond purchases by the central bank, (ii) the share of long-term debt in total government debt as an indicator of long-term bond supply and, after deducing the amount held by the central bank, the measure of private-sector holding of long-term government debt, and (iii) the expected period-on-period return on long-term bonds, which we calculate from current and three-month-ahead swap rates on 10-year government bonds. The construction of the latter series is consistent with our modelling assumption that agents are not obliged to hold longterm bonds to maturity and can, instead, trade these bonds in the secondary market at each period in time. We set the steady-state portfolio share of long-term to short-term government debt to 0.913 in line with the average of outstanding EA government debt over the sample period. The data on swap rates of EA government bonds determine the yield spread between short-term and long-term bonds.

The results displayed in the following sections treat ECB QE as an AR(2) shock for which the estimated parameters provide a hump-shaped path of central bank holdings of long-term gov-

\footnotetext{
${ }^{9}$ See also Planas et al. (2015) for a detailed description on the theory and practice of slice sampling.
} 
ernment debt. The AR(2) specification follows Carlstrom et al. (2017) and captures the expectation of a further expansion of the central bank balance sheet in the future; i.e., current bond purchases being followed by additional purchases in the future, as announced by the central bank at the start of the programme. As a sensitivity check, we also tested an $\mathrm{AR}(1)$ process for the $\mathrm{QE}$ shock in line with Chen et al. (2012) and De Graeve and Theodoridis (2016). The AR(1) specification implies that bond purchases by the central bank are not anticipated by the private sector (e.g., the agents react only to action, even though further steps have already been announced by the ECB), which mutes the impact of announcement effects with respect to further bond purchases. When examining the $\mathrm{AR}(1)$ specification, we estimated very high shock persistence (almost a random walk), which implies that agents expect no, or only a very gradual exit from, QE. In contrast, the $\mathrm{AR}(2)$ process is closer to agents' expectations, being based on the initial QE announcement, which implied a continuation of asset purchases during several quarters and a gradual exit in the medium term.

\section{Posterior Parameter Estimates ${ }^{10}$}

We choose priors for the non-QE related elements according to the nested model of Kollmann et al. (2016). It is crucial that the parameter on portfolio adjustment costs $\left({ }_{b}\right)$ be identified accurately, as it determines the impact of QE on the spread between short-term and long-term bond yields in the model. We resort to two approaches: one where prior information related to the performance of QE is used and another where we specify a uniform distribution. The second approach is preferable if one is fully agnostic about the prior. In the first approach, we set the prior for ${ }_{b}$ to a mean of $15 / 10000$ with standard deviation $6 / 10000$, which is in line with the calibrated value in Priftis and Vogel (2016) and captures the range of changes in interest spreads between short and long- term bonds around the time of the ECB's QE announcement. ${ }^{11}$

\footnotetext{
${ }^{10}$ The presentation of the results focuses on the role of QE and the related parameter estimates, impulse responses and historical decompositions. Broader discussion of results can be found in Kollmann et al. (2016) and the related online appendix, including predicted business-cycle statistics (standard deviations and cross-correlations of key macro variables); these statistics are broadly consistent with empirical statistics.

${ }^{11}$ The prior mean for ${ }_{b}$ is smaller, but in line with two other DSGE studies focusing on US Fed QE: De Graeve and Theodoridis (2016) choose a prior mean of 0.05 for the elasticity of the term spread to bond supply; Chen et al. (2012) choose a prior mean of 0.015 . The model of Chen et al. (2012) includes the additional parameter of bond market segmentation, however, which also impacts the effects of QE to the real economy. Harrison (2012) is an upper bound in the literature and sets the prior mean of the elasticity to 0.1 , but he does so in a stylised NewKeynesian model without investigating the impact of a particular episode of QE policy.
} 
Table 1: Prior and posterior distributions of key estimated EA model parameters.

\begin{tabular}{|c|c|c|c|}
\hline \multirow[t]{2}{*}{ Description } & \multicolumn{2}{|c|}{ Prior Distribution } & \multirow{3}{*}{$\begin{array}{c}\text { Posterior Distribution } \\
\text { Mode (Std.) }\end{array}$} \\
\hline & Dist. & Mean (Std.) & \\
\hline \multicolumn{3}{|l|}{ Preferences } & \\
\hline Consumption habit persistence & $\mathrm{B}$ & $0.5(0.20)$ & $0.90(0.02)$ \\
\hline Risk aversion & G & $1.5(0.20)$ & $1.54(0.17)$ \\
\hline Inverse Frisch elasticity of labour supply & G & $2.5(0.50)$ & $2.09(0.44)$ \\
\hline Import price elasticity & G & $2(0.4)$ & $2.54(0.28)$ \\
\hline Share of Ricardian households & $\mathrm{B}$ & $0.65(0.10)$ & $0.82(0.04)$ \\
\hline \multicolumn{4}{|l|}{ Nominal and real frictions } \\
\hline Portfolio adjustment costs & $\mathrm{G}$ & $0.0015(0.0006)$ & $0.0007(0.0002)$ \\
\hline Price adjustment cost & G & $60(40)$ & $42.6(9.25)$ \\
\hline Employment adjustment cost & $\mathrm{G}$ & $60(40)$ & $4.58(1.07)$ \\
\hline Nominal wage adj. cost & $\mathrm{G}$ & $5(2)$ & $5.55(1.48)$ \\
\hline \multicolumn{4}{|l|}{ Monetary policy } \\
\hline Interest rate persistence & $\mathrm{B}$ & $0.7(0.12)$ & $0.80(0.03)$ \\
\hline Response to inflation & $\mathrm{B}$ & $2(0.4)$ & $1.61(0.19)$ \\
\hline Response to GDP & $\mathrm{B}$ & $0.5(0.2)$ & $0.06(0.02)$ \\
\hline \multicolumn{4}{|l|}{ Autocorrelations of shocks } \\
\hline QE AR(1) (purchases of long-term bonds) & $\mathrm{N}$ & $1.8(0.4)$ & $1.75(0.10)$ \\
\hline QE AR(2) (purchases of long-term bonds) & $\mathrm{N}$ & $-0.8(0.3)$ & $-0.76(0.09)$ \\
\hline Bond risk premium & $\mathrm{B}$ & $0.5(0.20)$ & $0.87(0.05)$ \\
\hline Domestic price mark-up & $\mathrm{B}$ & $0.5(0.20)$ & $0.54(0.13)$ \\
\hline \multicolumn{4}{|l|}{ Standard deviations (\%) of innovations } \\
\hline Monetary policy & $\mathrm{B}$ & $1(0.40)$ & $0.09(0.01)$ \\
\hline QE (purchases of long-term bonds) & G & $1(0.40)$ & $1.12(0.17)$ \\
\hline Investment risk premium & $\mathrm{G}$ & $0.1(0.40)$ & $0.30(0.05)$ \\
\hline Bond risk premium & G & $1(0.40)$ & $0.17(0.09)$ \\
\hline Domestic price mark-up & $\mathrm{G}$ & $2(0.80)$ & $4.46(1.07)$ \\
\hline
\end{tabular}

Notes: Col. (1) lists model parameters and shocks. Cols. (2)-(3) indicate the prior distribution function (B: Beta distribution; G: Gamma distribution). Cols. (4)-(5) show the mode and the standard deviation (Std) of the posterior distributions of EA parameters.

With both prior choices, the posterior mode of the estimation converges to the same point, which suggests that the data are informative for successfully identifying the parameter. ${ }^{12}$ The posterior estimates of key model parameters for the EA are reported in Table 1. These estimates are based on the unconstrained linearised version of the model and also used for the solution with an occasionally binding constraint.

\footnotetext{
${ }^{12}$ See Figure C. 1 in the online appendix.
} 
The steady-state consumption share of the Ricardian household is estimated at 0.82 . Estimated habit persistence in consumption is high (0.90), which indicates a sluggish adjustment of consumption to income shocks. The risk aversion coefficient is in the range of 1.5 and the inverse of the elasticity of labour supply is estimated to be 2.1. The estimated price elasticity of aggregate imports is 2.5. The model estimates also suggest substantial nominal price and wage stickiness. The estimated interest rate rule indicates a strong response of the EA policy rate to domestic inflation, and a weak response to domestic output. Important in our context, the posterior estimate of the adjustment cost parameter attached to the maturity structure of the private sector portfolio of government debt is 0.0007 . The fiscal feedback rules for government transfers (not shown in Table 1) exhibit very weak responses to public debt and deficit levels. The estimates also suggest that most exogenous variables are highly serially correlated. The model properties discussed in what follows are evaluated at the posterior mode of the model parameters.

\section{QE in the Unconstrained Model}

This section provides results on the impact of QE for the unconstrained linearised version of our model. The discussion focuses on impulse responses and shock decompositions for real GDP growth and inflation. Using the unconstrained linearised model implies that the standard monetary policy (Taylor) rule is operational at any period of time. An operational Taylor rule offsets part of effective QE as it reacts to rising output growth and inflation by tightening short-term interest rates.

\subsection{Dynamic effects of QE shocks}

Figure 1 provides impulse responses of EA endogenous variables for a positive QE shock that illustrate the transmission of $\mathrm{QE}$ in the model. More precisely, the shock is a purchase of longterm government bonds by the central bank that is financed by additional liquidity. The initial shock is an increase in central bank holdings of long-term bonds by $1 \%$ of quarterly GDP. Given the specification of QE as an estimated $\mathrm{AR}(2)$ process, the initial purchase (announcement) implies a further extension of the central bank's balance sheet by another 12 quarters (3 years), until it reverses to a slow but gradual decline (exit) of the initial balance sheet extension. 

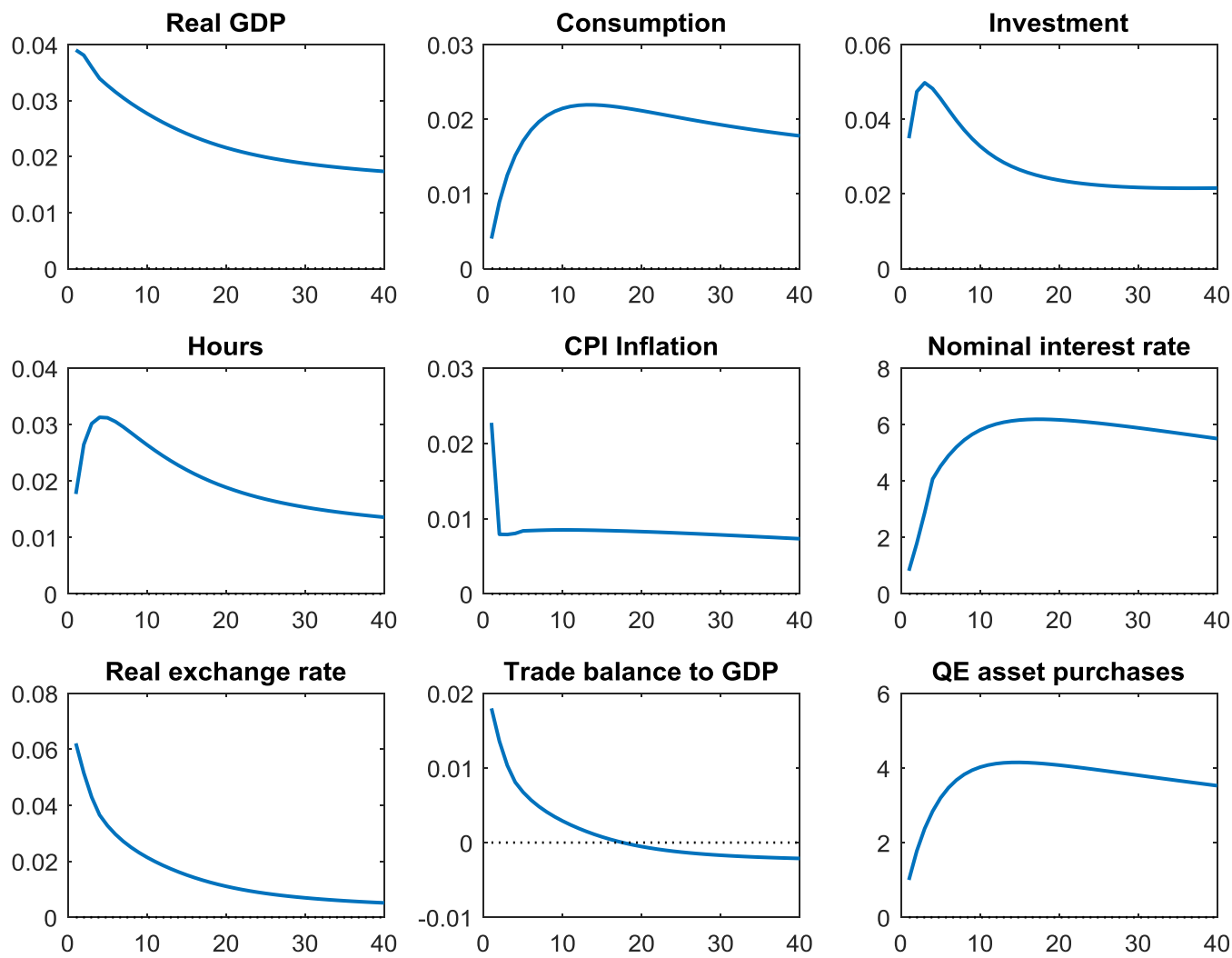

Note: Time intervals on the $\mathrm{x}$-axis are quarters; units on the y-axis are \%, except for inflation and the trade balance (both pp) and the short-term nominal interest rate (bp). The initial QE shock is $1 \mathrm{pp}$ of quarterly real GDP.

The purchase of long-term government debt by the central bank reduces the amount of long-term debt available to private investors. Given the preference of private investors for a maturity mix, i.e., imperfect substitutability between short-term and long-term bonds, the price of long-term bonds rises; their expected yield consequently declines. The decline in the yield of long-term bonds leads to portfolio rebalancing towards equity and foreign assets. Higher demand for equity lowers the equity premium and causes an increase in private investment, as shown in Figure 1. Higher demand for foreign assets causes depreciation of the domestic currency (an increase in the real exchange rate in Figure 1 corresponds to real effective depreciation), which leads to an improvement in the EA trade balance. The declining yield on long-term bonds also reduces private savings as private investors are less inclined to invest in short-term bonds away from the preferred maturity mix in the portfolio; the decline in savings raises private consumption. The joint increase in consumption, investment and net exports implies an increase in real GDP and (demand-driven) inflation. Note that the formulation of the central bank balance sheet expansions as 
an $\operatorname{AR}(2)$ process translates into a hump-shaped decline in the equity premium and the savings rate, which is behind the hump-shaped response of investment and consumption. Higher investment in productive capital raises the capital stock and the productivity of workers, so that labour demand and employment increase and real wages rise to some extent. Note that the efficiency of QE in Figure 1 is dampened by an offsetting response of the short-term policy rate. Given the positive impact of QE on activity and inflation, standard monetary policy as captured by the Taylor rule becomes less expansionary than in the non-QE baseline. Section 7 below will present corresponding impulse responses with binding ZLB constraint, i.e., without tightening of shortterm policy rates.

\subsection{Decomposing EA output growth and inflation}

To quantify the role of different shocks as drivers of output and inflation, we plot the estimated contribution of the different shocks to year-on-year real GDP growth (Figure 2) and to the yearon-year growth of the GDP deflator (Figure 3). To focus the discussion on the contribution of QE, we group the remaining shocks coarsely in three groups: domestic demand shocks (which include financial shocks affecting consumption, investment and net export demand, as well as fiscal shocks); domestic supply shocks (productivity and price and wage mark-up shocks); and trade and foreign shocks (containing shocks to trade demand and mark-ups and to foreign demand and supply, including oil price shocks). The black solid line presents the data, the blue surface the contribution of the respective group of shocks.

Regarding the pre-QE era, our estimated model mirrors the findings in Kollmann et al. (2016) (see Figure 2) for explaining the fluctuations in GDP growth and the EA double-dip recession. In particular, a large share of the GDP growth fluctuations in 1999-2017 is attributed to domestic demand shocks (in particular those driving investment demand), whereas the role of domestic supply shocks in the decomposition is much smaller. Trade and foreign shocks have contributed to negative growth during the 2009 recession (low external demand and decline in trade), but have supported GDP growth in more recent years (global recovery).

Most important in our context, the decomposition points to a positive impact of EA QE as captured in our model on EA growth from 2015 onwards, i.e., taking into account changes in the ECB balance sheet up to 2017q1. The impact of QE to GDP growth builds in early 2015 and per- 
sists in 2016. Figure 2 suggests a contribution of EA QE to annual EA real GDP growth of $0.3 \mathrm{pp}$ in both 2015 and $2016 .^{13}$

Figure 2: Decomposition of year-on-year growth of EA real GDP
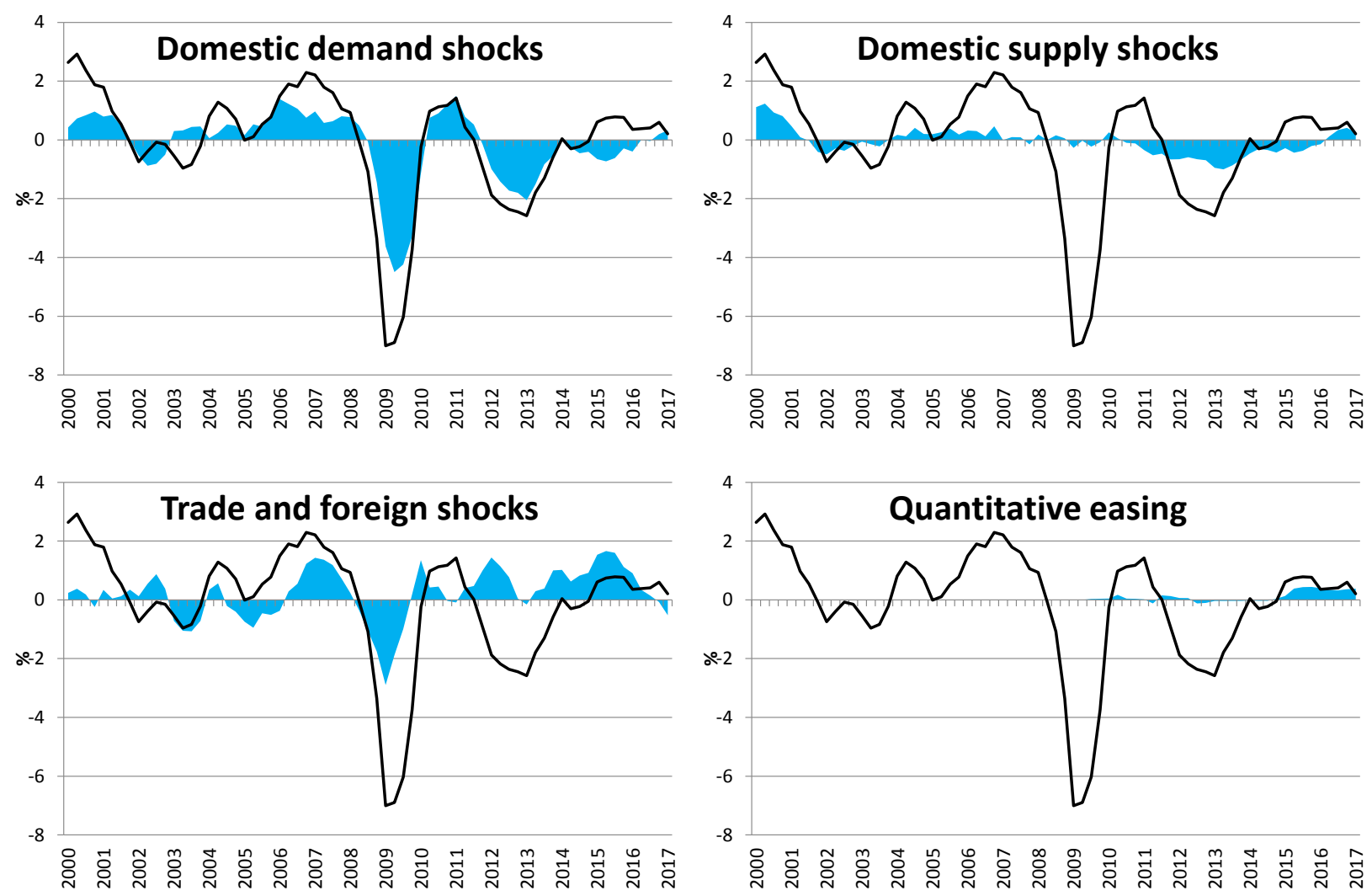

Figure 3 presents a decomposition for consumer price index (CPI) inflation. In line with Kollman et al. (2016), the results suggest a more balanced role of domestic demand and supply shocks in explaining the fluctuations in CPI inflation. The pre-crisis demand boom has added to inflation pressure, whereas the following contraction of domestic demand has pushed inflation down. Domestic supply shocks, notably negative productivity trends and the sluggish adjustment of wages and prices, have upheld inflation more in recent years according to the decomposition. The group of trade and foreign shocks has contributed negatively to inflation through lower export demand during the global recession, falling import prices (including oil) more recently, and nonfundamental changes in the euro exchange rate.

The estimated contribution of QE to annual EA CPI inflation is $0.3 \mathrm{pp}$ in 2015 and $0.6 \mathrm{pp}$ in 2016. The sizeable QE contributions to real GDP growth and inflation in the EA occur despite

\footnotetext{
${ }^{13}$ Note that the panels for QE in Figures 2 and 3 show smaller positive growth and inflation contributions already before 2015, which are due to (smaller) variations in the central bank holding of long-term debt prior to 2015 that are captured by the same shock but are not part of the programme initiated in 2015.
} 
the fact that effective QE triggers a tightening of standard monetary policy in the unconstrained linearised "normal times" model. As will be discussed in the following section, QE effects are stronger when accounting for the ZLB constraint.

Figure 3: Decomposition of year-on-year EA CPI inflation
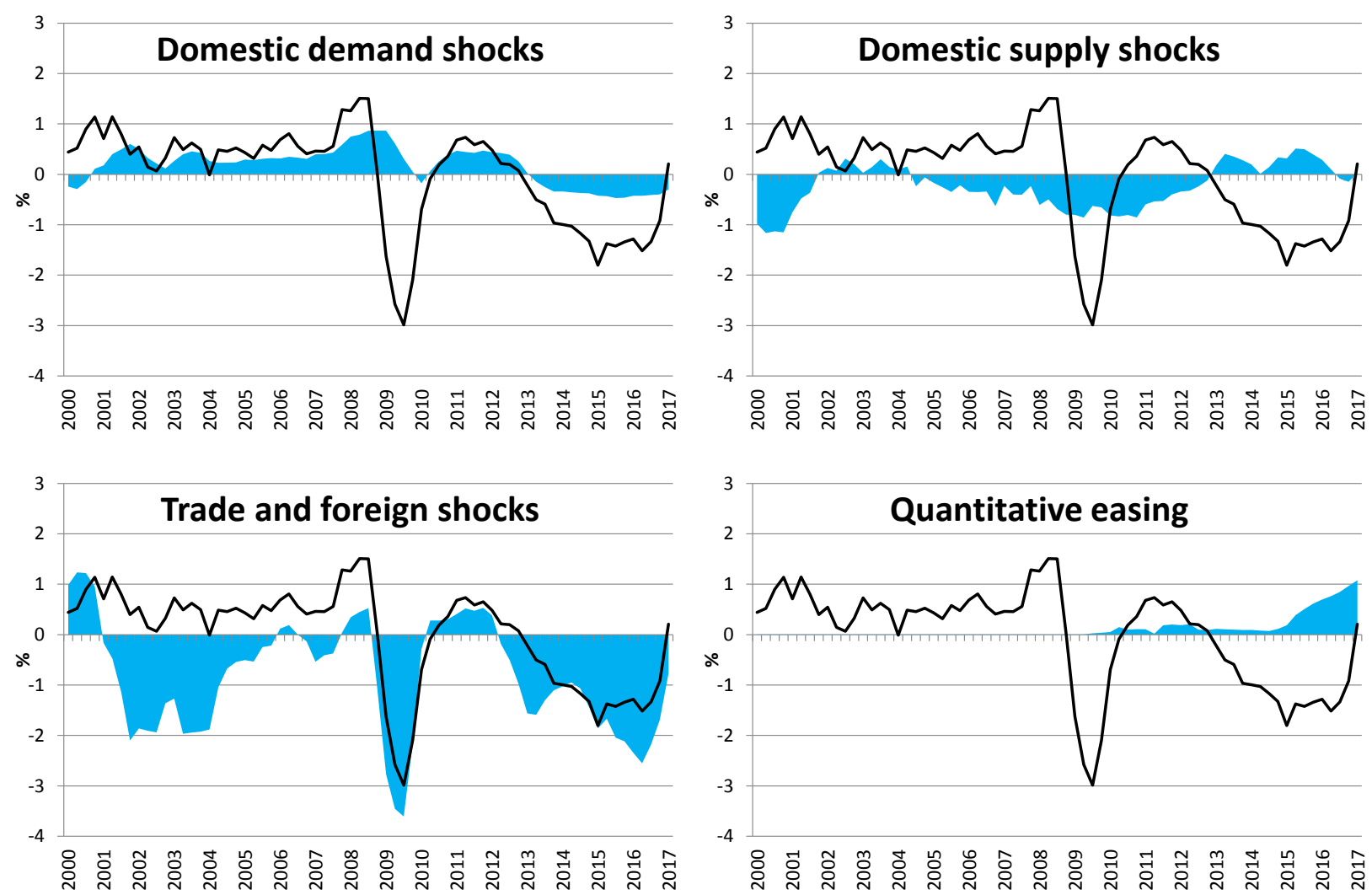


\section{QE in the Model with an Occasionally Binding Constraint}

In this section we assess the contribution of QE when we allow the zero-bound on monetary policy to be occasionally binding. A binding ZLB implies that the target ("shadow") policy rate is below the lower bound. By implication, an increase in output and inflation through QE or other factors does not lead to tightening of the short-term rate while the constraint is binding, i.e., while the shadow rate remains below the lower bound.

\subsection{Implementation of the occasionally binding constraint}

We use the OccBin solution method developed by Guerrieri and Iacoviello (2015) to treat the occasionally binding constraint via a piecewise linear solution. Moreover, we use an algorithm as in Giovannini and Ratto (2017) to obtain smoothed estimates of latent variables as well as the sequence of regimes along the historical sample. ${ }^{14}$ We set the lower bound for quarterly shortterm interest rates at $0.0125 \%$, in line with the annualised rate of $0.05 \%$, at which the ECB's main refinancing operations paused in 2014-15 after a sequence of consecutive rate reductions since 2011. The unconstrained nominal interest rate $i_{k t}^{N C}$ follows the usual Taylor rule without monetary shock:

$$
i_{k t}^{N C}-\bar{\imath}=\rho^{i}\left(i_{k t-1}-\bar{l}\right)+\left(1-\rho^{i}\right)\left(\eta^{i \pi}\left(0.25\left(\sum_{r=0}^{3} \pi_{k t-r}^{c, v a t}\right)-\bar{\pi}^{c, v a t}\right)+\eta^{i y}\left(\tilde{y}_{k t}\right)\right)
$$

As long as the actual policy rate is above the lower bound, the nominal interest rate is:

$$
i_{k t}=i_{k t}^{N C}+u_{k t}^{i n o m}
$$

If $i_{k t}^{N C} \leq i^{L B}$ the policy rate is constrained:

$$
i_{k t}=i^{L B}+u_{k t}^{i n o m}
$$

The variable $i_{k t}^{N C}$ acts as a "shadow" interest rate under a constrained regime. Under the OccBin algorithm, it allows it to be determined endogenously when the constraint is no longer binding. ${ }^{15}$ The algorithm used for estimating latent variables yields initial conditions and a sequence of

\footnotetext{
${ }^{14}$ We use the algorithm by Giovannini and Ratto (2017) to obtain estimated latent variables and a corresponding sequence of historical regimes. The algorithm works as follows: It guesses an initial sequence of historical regimes and computes the sequence of state-space matrices following the piecewise linear solution by Guerrieri and Iacoviello (2015). Given the state-space matrices, the Kalman filter is used to estimate the smoothed variables and shocks, which endogenously determine a new sequence of regimes. The algorithm stops when the new sequence of regimes is equal to the previous one. In our case, the algorithm converged after three iterations.

${ }^{15}$ We still use an exogenous monetary shock under the constrained regime in order to keep observing the actual policy rate in the data. The shock does not affect the behaviour of the piecewise linear solution in terms of transmission mechanisms under the ZLB constraint.
} 
smoothed shocks that are consistent with the observables and take into account the occasionally binding constraint. The sequence of regimes is reported in Table 2.

Table 2: Estimation of the historical sequence of occasionally binding regimes in 2013q1-2017q1

\begin{tabular}{|c|c|c|}
\hline Time & $\begin{array}{r}\text { Regime } \\
\text { sequence }^{1}\end{array}$ & $\begin{array}{r}\text { Starting period } \\
\text { of regime }\end{array}$ \\
\hline $2013 q 1$ & 0 & 1 \\
\hline $2013 q 2$ & 0 & 1 \\
\hline $2013 q^{3}$ & 0 & 1 \\
\hline $2013 q 4$ & 0 & 1 \\
\hline $2014 q 1$ & 0 & 1 \\
\hline $2014 q 2$ & 0 & 1 \\
\hline $2014 q^{3}$ & 0 & 1 \\
\hline $2014 q 4$ & 10 & 14 \\
\hline $2015 q 1$ & 10 & 15 \\
\hline $2015 q 2$ & 10 & 13 \\
\hline $2015 q^{3}$ & 10 & 13 \\
\hline $2015 q 4$ & 10 & 14 \\
\hline $2016 q 1$ & 10 & 15 \\
\hline $2016 q 2$ & 10 & 13 \\
\hline $2016 q^{3}$ & 10 & 13 \\
\hline $2016 q 4$ & 10 & 12 \\
\hline 2017q1 & 0 & 1 \\
\hline
\end{tabular}

Notes: (First column) $0=$ unconstrained, $1=$ constrained. [1 0 ] indicates a constrained regime. (Second column) Periods for which the regime starts: [1 5] indicates a constrained regime for 4 periods.

Based on our definition of the ZLB as a $0.05 \%$ annual nominal interest rate, EA monetary policy is constrained from $2014 \mathrm{q} 4$ onwards. While our simulation indicates a continued constrained regime in 2016q4, which is expected to last until 2017q1, monetary policy in 2017q1 is effectively no longer constrained.

\subsection{Dynamic effects of QE shocks at the ZLB}

Based on the sequence of regimes, we perform impulse response functions (IRFs) with a ZLB that are consistent with the estimated timing and duration of the constrained regime. In particular, 
we perform the following exercise: We use as a starting point the smoothed variables in $2015 \mathrm{q} 1$, which is a period of constrained monetary policy according to Table 2 and the official start of QE. We shut off all QE shocks and simulate the model with all other shocks. Then we perform another simulation adding a positive ECB QE shock of the same size as in Figure 1, i.e., longterm bond purchases of $1 \%$ of steady-state quarterly EA GDP. The difference between the two simulations provides the IRF of the ECB QE shock under the constrained regime. The result is shown in the comparison between the linear (unconstrained) and piecewise linear (constrained) IRFs in Figure 4.

Figure 4: IRF for positive EA QE shock under unconstrained and constrained monetary policy
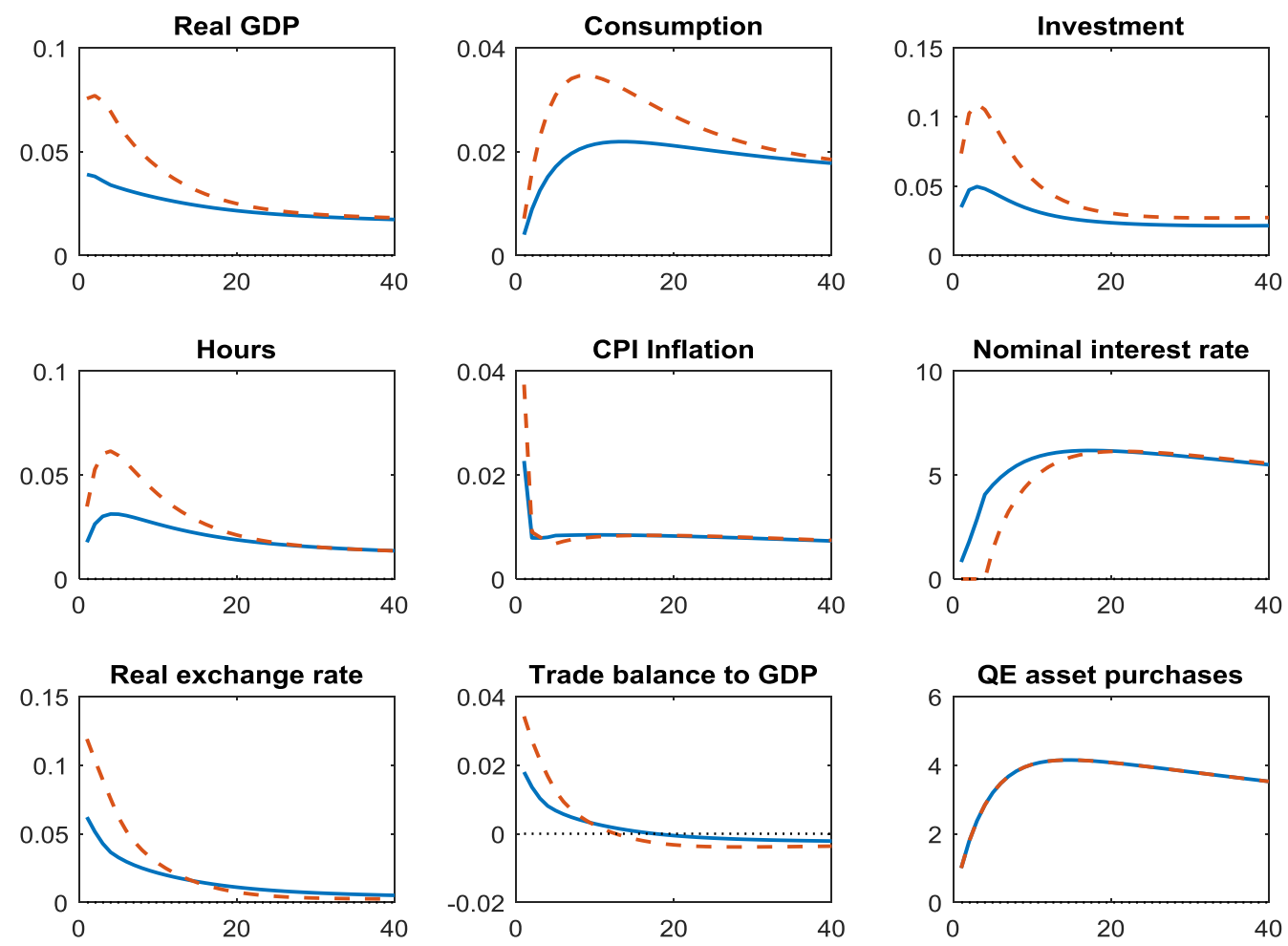

Note: Solid (blue) is the linear (unconstrained) model, dashed (red) the piecewise linear model (ZLB). The linear solution is equivalent to the IRFs in Figure 1.

Given the starting point of our simulations in 2015q1 and the sequence of regimes in Table 2, monetary policy in $2015 \mathrm{q} 1$ is expected to be constrained for four quarters, although from an expost perspective, it is constrained until 2016q4. Figure 4 captures the expectation of monetary policy being constrained for four quarters and going back to "normal" times from 2016q1 on- 
wards by a gradual increase of the constrained towards the unconstrained nominal interest rate response after four quarters. The change back to the "normal regime" is the consequence of softening contractionary forces, i.e., the abating of contractionary shocks and of the effectiveness of QE, i.e., it is not the result of an exogenous regime switch. The IRFs suggest that the impact of the QE shock on real GDP (quarterly $0.08 \%$ instead of $0.04 \%$ on impact) and CPI inflation $(0.04$ pp instead of $0.02 \mathrm{pp}$ on impact) doubles in the zero-bound environment.

\subsection{Decomposing EA output growth and inflation}

As for the unconstrained model, we investigate the shock contributions to the observed data that are consistent with the piecewise linear solution, i.e., we provide an extension of the standard historical shock decompositions to the case of occasionally binding regimes. In this context, the contribution of individual smoothed shocks is not the mere additive superposition of each shock. Instead, it is a non-linear function of the whole set of shocks simultaneously affecting the economy. Hence, the contribution of one shock is conditional on the sequence and combination of shocks simultaneously hitting the economy. ${ }^{16}$

We use the complement/residual contribution to account for the impact of the ZLB on the contribution of shocks to observed variables. In practice, we compute the contribution of QE by setting the QE shock to zero and perform simulations using initial conditions and the sequence of all the other shocks. The contribution of QE will be the complement/residual of this simulation to the smoothed variable. ${ }^{17}$

Figure 5 compares the contribution of QE to year-on-year real GDP growth and CPI inflation in the EA under the linear (unconstrained) solution and the piecewise linear (ZLB constraint) solution, respectively. Accounting for the temporarily binding ZLB strengthens the positive contribution of QE to real GDP growth and inflation in 2015-16. Compared with the linearised "normal times" solution, the average impact of QE on annual real GDP growth rises from $0.3 \mathrm{pp}$ to $0.6 \mathrm{pp}$ in 2015 and from $0.3 \mathrm{pp}$ to $0.7 \mathrm{pp}$ in 2016. The impact on annual CPI inflation rises from $0.3 \mathrm{pp}$ to $0.4 \mathrm{pp}$ in 2015 and from $0.6 \mathrm{pp}$ to $0.8 \mathrm{pp}$ in 2016 . The more positive contribution of QE under the ZLB derives from the absence of a countervailing tightening of monetary policy according to the Taylor rule that would occur in "normal" times in the linearised model.

\footnotetext{
${ }^{16}$ In general, we can consider two definitions that generalise the concept of shock contributions in the non-linear case, which degenerate to the standard shock decomposition for the linear case: The conditional contribution and the complement contribution. See Giovannini and Ratto (2017) for a detailed description of both methods.

${ }^{17}$ Note that each of these simulations provides a different sequence of regimes, which in general will be different from the historical one. The complement/residual contribution triggers key non-linear features associated to the interaction between shock realisation and the occasionally binding constraints.
} 
Figure 5: QE contribution to year-on-year EA real GDP growth and CPI inflation in linear and piecewise linear solution
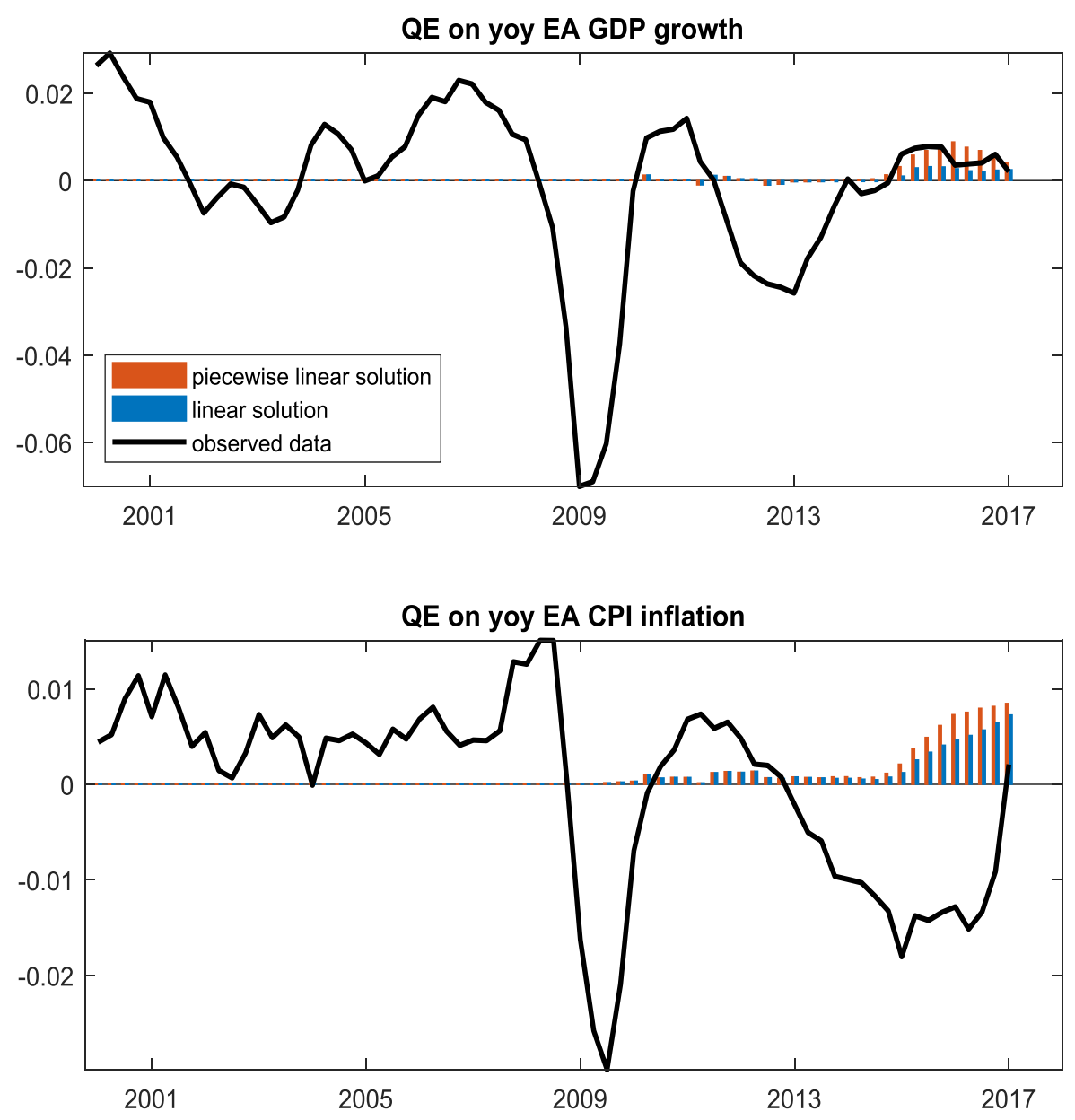

Note: Real GDP growth and CPI inflation are both shown as deviations from the steady state, which is calibrated as the mean over the sample period from 1999q1 to $2017 \mathrm{q} 1$. In both sub-plots, 0.01 on the y-axis corresponds to $1 \mathrm{pp}$.

Along with the decomposition of GDP growth, Figure 6 displays the contribution of QE to the growth rate of those variables that are the main transmission channels of $\mathrm{QE}$ in our portfolio rebalancing framework, namely consumption (reduced savings), investment (lower equity premium) and the real exchange rate (currency depreciation). The figure indicates a particularly pronounced impact on EA investment growth and a sizeable impact on consumption growth and real effective exchange rate (REER) depreciation. It also indicates a frontloading of the impact on investment and REER, which is the result of forward-looking behaviour in combination with anticipation of further asset purchases that is embodied in the $\operatorname{AR}(2)$ specification of the QE process. The impact on consumption growth is more gradual and delayed, due to the estimated high degree of habit persistence in consumption. 
Figure 6: Transmission channels of $Q E$ in linear and piecewise linear solution
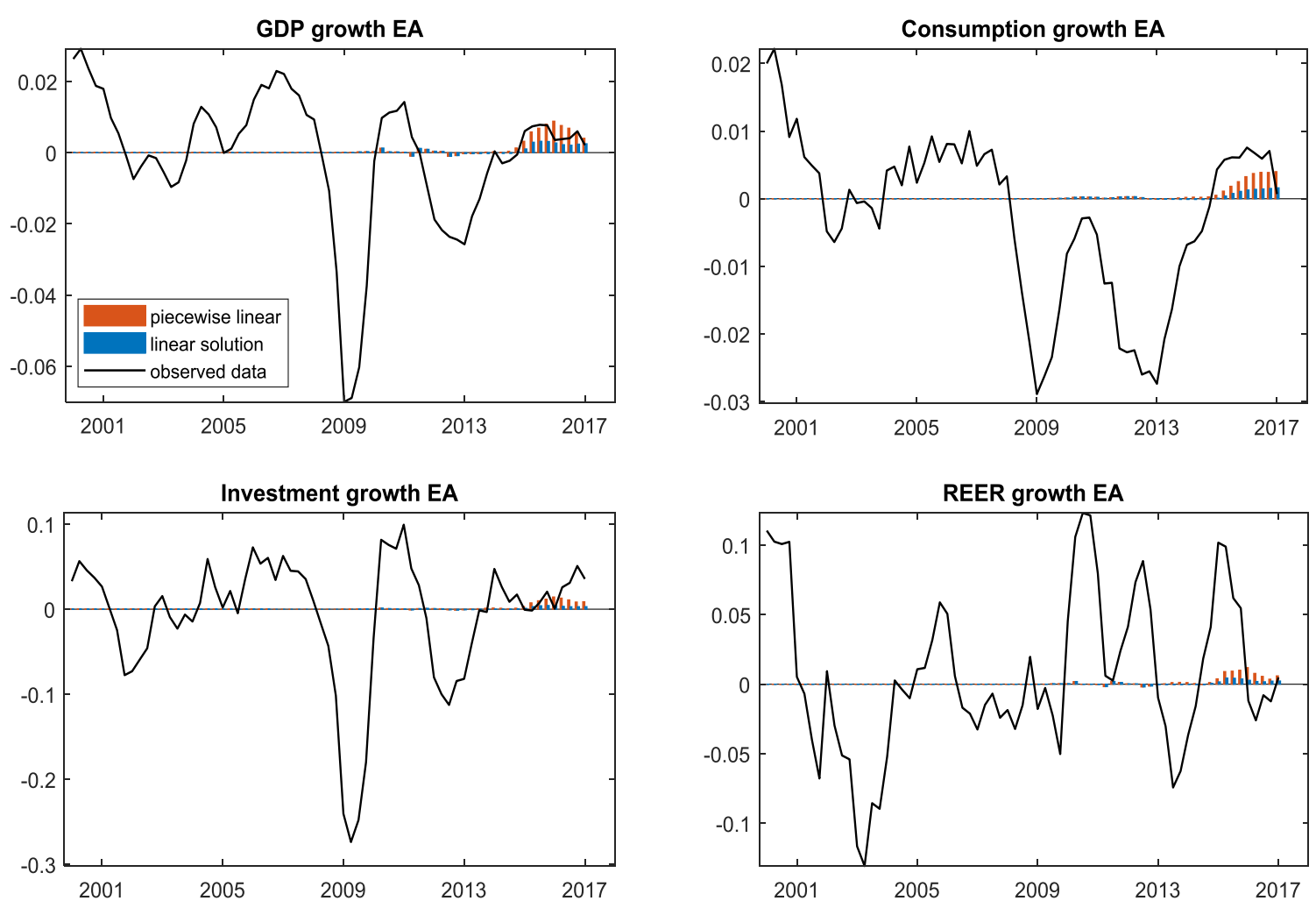

Note: All variables are shown in year-on-year percentage point deviations from the steady state, which is calibrated as the mean over the sample period from $1999 q 1$ to $2017 q 1$. An increase in REER corresponds to depreciation of EA versus RoW.

Finally, Figure 7 shows the impact of the central bank's asset purchases on the interest spread between the long-term government bonds (LT) and short-term government bonds (ST). The series are displayed relative to the sample average. The blue line is the data. The orange line is a counterfactual of how the spread would have evolved without central bank asset purchases according to our estimated model. The counterfactual suggests that, starting in 2015, QE has compressed the spread by up to 70 basis points. There are smaller differences between data and spreads already before 2015, which are due to variations in ECB bond holdings that are captured by the balance sheet data without being part of the expanded asset purchase programme. 


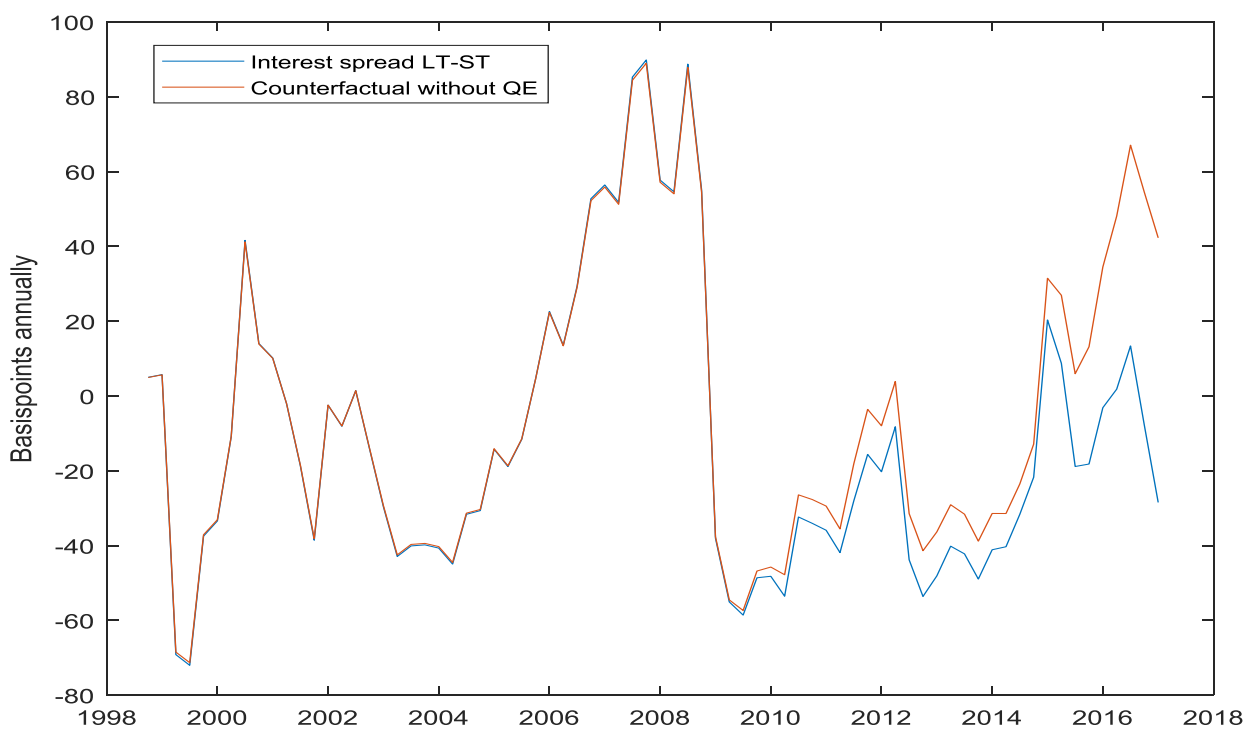

Note: The interest rate spread is defined as the interest rate on long-term bonds minus the interest rate on short-term bonds in annualised basis points. Blue lines are the data.

The effects of QE on EA GDP and inflation in our estimated model are comparable with existing literature for EA QE and comparable in order of magnitude with results from similar exercises for the US QE: Sahuc (2016) finds effects of ECB QE (9\% of EA GDP) on EA real GDP growth (inflation) of 0.2 (0.1 pp) in 2015-16 for short-term rates constant in 2015, whereas keeping the policy rate unchanged for another year raises the average growth (inflation) effect in 2015-16 to $0.6 \mathrm{pp}(0.6 \mathrm{pp})$. For the US, Chen et al. (2016) report GDP growth (inflation) effects of $0.1 \mathrm{pp}$ $(0.3 \mathrm{pp})$ of US QE measures of a volume of $4 \mathrm{pp}$ of GDP. De Graeve and Theodoridis (2016) report GDP growth (inflation) effects of $0.6 \mathrm{pp}(0.3 \mathrm{pp})$ of the Federal Reserve's "Operation Twist". Both studies work with scenarios in which short-term policy rates do not respond (immediately) to higher growth and inflation. Gertler and Karadi (2013) quantify the impact of US LSAP with a volume of $2.5 \%$ of GDP on output growth (inflation) to $1 \mathrm{pp}(1.5 \mathrm{pp})$ if policy rates remain unchanged, and $0.2 \mathrm{pp}(0.2 \mathrm{pp})$ if the standard monetary policy rule is active and partly offsets expansionary QE effects.

\section{Conclusion}

We have introduced imperfect substitutability between bonds of different maturities and central bank balance sheet operations in a New Keynesian open-economy DSGE model. We have estimated a two-region (EA and RoW) version of the model to assess the impact of the ECB's large- 
scale asset purchase programme $(\mathrm{QE})$ on economic activity and inflation in the EA. The detailed modelling of QE and portfolio adjustment enables us to capture a large number of the transmission channels put forward in the literature, including the saving, financing cost, and exchange rate channels. We use data on government debt stocks and yields across maturities to identify the parameter that governs portfolio adjustment in the private sector and yield, exchange rate and savings effects of central bank asset purchases. The shock decompositions for real GDP growth and CPI inflation in the EA suggest a positive annual contribution of ECB QE to EA output growth and inflation of up to $0.3 \mathrm{pp}$ and $0.6 \mathrm{pp}$ during 2015 and 2016 in the standard unconstrained ("normal times") model and up to $0.7 \mathrm{pp}$ and $0.8 \mathrm{pp}$, respectively, in the model that accounts for the endogenous temporarily binding zero-bound constraint.

\section{References}

Altavilla, C., G. Carboni, R. Motto (2015): "Asset purchase programmes and financial markets: lessons from the euro area," ECB Working Paper 1864.

Andrade, P., J. Breckenfelder, F. De Fiore, P. Karadi, O. Tristani (2016): "The ECB's asset purchase programme: an early assessment," ECB Working Paper 1956.

Andrés, J., D. López-Salido, E. Nelson (2004): "Tobin's imperfect asset substitution in optimizing general equilibrium," Journal of Money, Credit and Banking 36(4), 665-690.

Bluwstein, K., F. Canova (2016): "Beggar-thy-neighbor? The international effects of ECB's unconventional monetary policies," International Journal of Central Banking, 12(3), 69-121.

Carlstrom, C., T. Fuerst, M. Paustian (2017): "Targeting long rates in a model with segmented markets," American Economic Journal: Macroeconomics, 9(1), 205-242.

Chen, H., V. Cúrdia, A. Ferrero (2012): "The macroeconomic effects of large-scale asset purchase programmes," Economic Journal 122(564), F289-F315.

De Graeve, F., K. Theodoridis (2016): "Forward guidance, quantitative easing, or both?" National Bank of Belgium Working Paper 305.

De Santis, R. (2016): "Impact of the asset purchase programme on euro area government bond yields using market news," ECB Working Paper 1939.

Draghi, M. (2015): "Introductory statement to the press conference (with Q\&A), Frankfurt am Main, 22 January 2015, https://www.ecb.europa.eu/press/pressconf/2015/html/is 150122.en.html

Falagiarda, M. (2013): "Evaluating quantitative easing: A DSGE approach," MPRA Paper 49457, University Library of Munich. 
Gertler, M., P. Karadi (2013): "QE 1 vs. 2 vs. 3.: A framework for analyzing large-scale asset purchases as a monetary policy tool," International Journal of Central Banking 9(1), 5-53.

Giovannini, M., M. Ratto (2017): "Latent variables and real-time forecasting in DSGE models with occasionally binding constraints: Can non-linearity improve our understanding of the Great Recession?" mimeo.

Guerrieri, L., M. Iacoviello (2015): "OccBin: A toolkit for solving dynamic models with occasionally binding constraints easily," Journal of Monetary Economics 70, 22-38.

Harrison, R. (2012): "Asset purchase policy at the effective lower bound for interest rates," Bank of England Working Paper 444.

Harrison, R. (2017): "Optimal quantitative easing," Bank of England Working Paper 678.

Kollmann, R., B. Pataracchia, R. Raciborski, M. Ratto, W. Roeger, L. Vogel (2016): "The postcrisis slump in the Euro Area and the US: Evidence from an estimated three-region DSGE model," European Economic Review 88(C), 21-41.

Krishnamurthy, A., A. Vissing-Jorgensen (2011): "The effects of quantitative easing on interest rates: Channels and implications for policy," Brookings Papers on Economic Activity 43, 215287.

Liu, P., H. Mumtaz, K. Theodoridis, F. Zanetti (2015): "Changing macroeconomic dynamics at the zero lower bound," mimeo.

Neal, R. (2003): "Slice sampling," The Annals of Statistics 31(3), 705-767.

Planas, C., M. Ratto, A. Rossi (2015): "Slice sampling in Bayesian estimation of DSGE models," European Commission Joint Research Centre, available online:

http://www.dynare.org/DynareConference2015/papers/Ratto_Planas_Rossi.pdf.

Priftis, R., L. Vogel (2016): "The portfolio balance mechanism and QE in the euro area," Manchester School 84(S1), 84-105.

Ratto, M., W. Roeger, J. in 't Veld (2009): “QUEST III: An estimated open-economy DSGE model of the euro area with fiscal and monetary policy”, Economic Modelling 26(1), 222-233.

Sahuc, J.-G. (2016): "The ECB's asset purchase programme: A model-based evaluation," Economics Letters 145(C), 136-140.

Woodford, M. (2001): "Fiscal requirements for price stability," Journal of Money, Credit and Banking 33, 669-728. 


\section{A. Model Description}

We introduce elements of quantitative easing into a two-region world consisting of the euro area (EA) and the rest of the world (RoW). The EA region is rather detailed, while the RoW block, which also includes the US, is more stylised. ${ }^{18}$

The EA region assumes two (representative) households, a number of layers of firms and a government. EA households provide labour services to firms. One of the two households (savers, or "Ricardians") in each country has access to financial markets, and she owns her country's firms. The other (liquidity-constrained, or "non-Ricardian") household has no access to financial markets, does not own financial or physical capital, and in each period consumes only the disposable wage and transfer income. The preferences of both types of households exhibit habit formation in both consumption and leisure, a feature which allows for better capturing the persistence of the data.

There is a monopolistically competitive sector producing differentiated goods, using domestic labour and capital. The firms in the sector maximise the present value of dividends at a discount factor that is strictly larger than the risk-free rate and varies over time. This is a shortcut for capturing financial frictions facing firms; it can, for example, be interpreted as a "principal agent friction" between the owner and the management of the firm. Optimisation is subject to investment and labour adjustment costs and a varying capacity utilisation rate, which lets the model better capture the dynamics of the current account and other macro variables.

Total output is produced by combining the domestic differentiated goods bundle with energy input. EA wages are set by monopolistic trade unions. Nominal differentiated goods prices are sticky as are the wages paid to the workers. Fiscal authorities in the EA impose distortive taxes and issue debt.

The RoW block is simplified compared with the EA block. Specifically, the RoW consists of a budget constraint for the representative household, demand functions for domestic and imported goods (derived from constant elasticity of substitution (CES) consumption good aggregators), a production technology that uses labour as the sole factor input, and a New Keynesian Phillips curve. The RoW block abstracts from capital accumulation.

The behavioural relationships and technology are subject to autocorrelated shocks denoted by $\varepsilon_{t}^{x}$, where $x$ stands for the type of shock. $\varepsilon_{t}^{x}$ will generally follow an AR(1) process with autocorrelation coefficient $\rho^{x}<1$ and innovation $u_{t}^{x}$ :

\footnotetext{
${ }^{18}$ The EA block builds on, but is considerably different from the QUEST model of the EU economy (Ratto et al., 2009).
} 


$$
\left(\varepsilon_{t}^{x}\right)=\rho^{x}\left(\varepsilon_{t}^{x}\right)+u_{t}^{x}
$$

There is also a separate category of shocks, denoted $A_{t}^{x}$, whose logs are integrated of order $1 .{ }^{19}$ With the exception of the total factor productivity (TFP) shocks, these shocks are modelled as $\operatorname{ARIMA}(1,1,0)$ shocks. $^{20}$

We next present a detailed description of the EA block, followed by an overview of the RoW model block. Throughout the derivation, the following indexing convention will be preserved: indices $i$ and $j$ index firms and households, respectively. These indices will usually be dropped when the equilibrium conditions are derived, due to the representative household/firm assumption. Index $l$ indicates sovereign states or economic regions. Finally, index $k$ will always indicate the "domestic" economy. This index will be generally dropped for parameters (even if they are country-specific), but will be usually preserved for variables.

\section{A.1. EA households}

The household sector consists of a continuum of households $j \in[0 ; 1]$. There are two types of households: savers ("Ricardians", superscript $s$ ), who own firms and hold government and foreign bonds, and liquidity-constrained households (subscript $c$ ), whose only income is labour income and who do not save. The share of savers in the population is $\omega^{s}$.

Both households enjoy utility from consumption $C_{j k t}^{r}$ and incur disutility from labour $N_{j k t}^{r}$ $(r=s, c)$. On top of this, Ricardians' utility depends also on the financial assets held.

Date $t$ expected life-time utility of household $r$ is defined as:

$$
U_{j k t}^{r}=\sum_{s=t}^{\infty} \varepsilon_{k t}^{c} \beta^{s-t} u_{j k t}^{r}(\cdot)
$$

where $\beta$ is the (non-stochastic) discount factor (common for both types of households) and $\varepsilon_{k t}^{c}$ is the saving shock.

\section{A.1.1. Ricardian households}

The Ricardian households work, consume, own firms and receive nominal transfers $T_{j k t}^{S}$ from the government. Ricardians have full access to financial markets and are the only households who

\footnotetext{
${ }^{19}$ These, in particular, include the TFP shock and the final demand productivity shocks.

${ }^{20}$ TFP is driven by three shocks, see below.
} 
own financial assets $\frac{A_{j k t}}{P_{k t}^{c, v a t}}$ where $P_{k t}^{c, v a t}$ is consumption price, including VAT. ${ }^{21}$ Financial wealth of household $j$ consists of bonds $\frac{B_{j k t}}{P_{k t}^{c, v a t}}$ and shares $\frac{P_{k t}^{S} S_{j k t}}{P_{k t}^{c, v a t}}$, where $P_{k t}^{S}$ is the nominal price of shares in $t$ and $S_{j k t}$ the number of shares held by the household. It is assumed that households invest only in domestic shares.

$$
\frac{A_{j k t}}{P_{k t}^{c, v a t}}=\frac{B_{j k t}}{P_{k t}^{c, v a t}}+\frac{P_{k t}^{S} S_{j k t}}{P_{k t}^{c, v a t}}
$$

Bonds consist of domestic government bonds $\frac{B_{j k k t}^{g}}{P_{k t}^{c, v a t}}$, foreign bonds $\frac{e_{l k t} B_{j l k t}^{g}}{P_{k t}^{c, v a t}}$ and private risk-free bonds $\frac{B_{j k t}^{r f}}{P_{k t}^{c, v a t}}$ (in zero supply):

$$
\frac{B_{j k t}}{P_{k t}^{c, v a t}}=\frac{B_{j k t}^{r f}}{P_{k t}^{c, v a t}}+\sum_{l} e_{l k t} B_{j l k t}^{g}
$$

with $e_{l k t}$ the bilateral exchange rate and $e_{k k t} \equiv 1 .^{22}$

Total government bonds consist of long-term bonds $B_{j k k t}^{g, L}$ and short-term bonds $B_{j k k t}^{g, \mathrm{~S}}$ :

$$
B_{j k k t}^{g}=B_{j k k t}^{g, L}+B_{j k k t}^{g, S}
$$

From the outstanding long-term bonds $B_{j k k t}^{g, L, H}$ are held by the private sector and $B_{j k k t}^{g, L, C B}$ by the central bank:

$$
B_{j k k t}^{g, L}=B_{j k k t}^{g, L, H}+B_{j k k t}^{g, L, C B}
$$

Short-term and long-term bonds are imperfect substitutes in the model. In particular, households have a preference for holding a mix of short-term and long-term bonds, and deviations from the target value $\kappa$ for the ratio of long-term over short-term debt induce quadratic adjustment costs $\left(\gamma_{b}\right)$. The same formulation of portfolio preferences or adjustment costs has been used previously by, for example, Andrés et al. (2004), Falagiarda (2013), Harrison (2012), and Liu et al. (2015).

21 Note that $P_{k t}^{c, v a t}$ is related to $P_{k t}^{C}$, the private consumption deflator in terms of input factors, by the formula: $P_{k t}^{c, v a t}=\left(1+\tau_{k}^{C}\right) P_{k t}^{C}$ where $\tau^{c}$ is the tax on consumption.

${ }^{22}$ For simplicity, at this moment the model assumes only one type of foreign bond, $B_{\text {Rowkt }}^{g}$, issued by RoW and denominated in RoW currency. 
The budget constraint of a Ricardian household $j$ is given by:

$$
\begin{aligned}
& P_{k t}^{c, v a t} C_{j k t}^{s}+\frac{P_{k t}^{N} B_{k k t}^{g, L, H}}{P_{k t}^{Y}}\left(1+\frac{\gamma_{b}}{2}\left(\kappa \frac{B_{k k t}^{g, S}}{B_{k k t}^{g, L, H}}-1\right)^{2}\right)+\frac{B_{k k, t-1}^{g, S}}{P_{k t}^{Y}}+\frac{e_{l k t} B_{l k t-1}^{g}}{P_{k t}^{Y}}+\frac{B_{t}^{S}}{\left(1+i_{t}^{g}\right) P_{k t}^{Y}}=\left(1-\tau^{N}\right) W_{k t} N^{s}{ }_{j k t}^{s} \\
& +\left(1+i_{t-1}^{r f}\right) B_{j k t-1}^{r f}+\left(P_{k t}^{S}+P_{k t}^{Y} d_{k t}\right) S_{j k t-1}+d i v_{k t}+T_{j k t}^{s}-\operatorname{tax}^{s}{ }_{j k t}+\frac{c B_{k k t-1}^{g, L, H}}{P_{k t}^{Y}}+\frac{\delta_{b} P_{k t}^{N} B_{k k t-1}^{g, L, H}}{P_{k t}^{Y}}
\end{aligned}
$$

where $W_{k t}$ is the nominal wage rate, $P_{k t}^{Y}$ is GDP price deflator, $i_{l t-1}^{g}$ are interest rates on government bonds of region $l, i_{t-1}^{r f}$ is interest rate on risk-free bond, $T_{j k t}^{s}$ are government transfers to savers and $\operatorname{tax}^{s}{ }_{j k t}$ are lump-sum taxes paid by savers. Note that savers own all the firms in the economy. $d i v_{k t}$ represent the profits of all firms other than differentiated goods producers (the latter producers transfer profits to savers by paying dividends $d_{k t}$ ).

The price in period $t$ of a short-term (1-period) bond of nominal value $B_{k k t}^{g, s}$ is $B_{k k t}^{g, S} /\left(1+i_{t}^{g}\right)$, with $i_{t}^{g}$ being the short-term nominal interest rate. Following Woodford (2001), long-term government debt is modelled through bonds for which the nominal coupon $c$, which is a fraction of the principal, depreciates over time at rate $\delta_{b}$. The price in period $t$ of a long-term bond issued in $t\left(P_{k t}^{N}\right)$ equals the discounted value of future payments:

$$
P_{k t}^{N}=\sum_{n=0}^{T} \frac{\delta_{b}^{n}}{\left(1+i^{g}\right)^{1+n}} c
$$

where $\mathrm{T}$ is the maturity period of the bond.

We define the gross nominal return on domestic shares as:

$$
1+i_{k t}^{S}=\frac{P_{k t}^{S}+P_{k t}^{Y} d_{k t}}{P_{k t-1}^{S}}
$$


The instantaneous utility functions of savers, $u^{s}(\cdot)$, is defined as:

$$
\begin{aligned}
u^{s}\left(C_{j k t}^{s}, N_{j k t}^{S},\right. & \left.\frac{U_{j k t-1}^{A}}{P_{k t}^{C, v a t}}\right) \\
& =\frac{1}{1-\theta}\left(C_{j k t}^{S}-h C_{k t-1}^{s}\right)^{1-\theta}-\frac{\omega^{N} \varepsilon_{k t}^{U}}{1+\theta^{N}}\left(C_{k t}^{s}\right)^{1-\theta}\left(N_{j k t}^{S}-h_{N} N_{k t-1}^{s}\right)^{1+\theta^{N}} \\
& -\left(C_{k t}^{s}-h C_{k t-1}^{s}\right)^{-\theta} \frac{U_{j k t-1}^{A}}{P_{k t}^{c, v a t}}
\end{aligned}
$$

where $C_{k t}^{s}=\int C_{j k t}^{s}, C_{k t}=\omega^{s} C_{k t}^{s}+\left(1-\omega^{s}\right) C_{k t}^{c} ; h, h_{N} \in(0 ; 1)$ measure the strength of the external habits in consumption and labour and $\varepsilon_{k t}^{U}$ is the labour supply (or wage mark-up) shock. The disutility of holding financial assets, $U_{j k t-1}^{A}$, is defined as:

$$
\begin{aligned}
U_{j k t-1}^{A}= & \sum_{l}\left(\left(\alpha_{l k}^{b B 0}+\varepsilon_{l k t-1}^{B}\right) e_{l k t-1} B^{g}{ }_{j l k t-1}\right)+ \\
& \left(\left(\alpha_{k}^{s S 0}+\varepsilon_{k t-1}^{S}\right) P_{s t-1}^{S} S_{j k t-1}\right)
\end{aligned}
$$

The Ricardian household problem leads to the following first-order conditions (FOCs). ${ }^{23}$ The FOC with respect to (w.r.t.) savers' consumption produces:

$$
\varepsilon_{k t}^{C}\left(C_{k t}^{s}-h C_{k t-1}^{s}\right)^{-\theta}=\lambda_{k t}^{s}
$$

where $\lambda_{k t}^{S}$ is the Lagrange multiplier on the budget constraint.

FOC w.r.t. domestic risk-free bond:

$$
\beta E_{t}\left[\frac{\lambda_{k t+1}^{S}}{\lambda_{k t}^{S}} \frac{1+i_{k t}^{r f}}{1+\pi_{k t+1}^{C, v a t}}\right]=1
$$

FOC w.r.t. domestic short-term government bonds:

$$
\beta E_{t}\left(\frac{\lambda_{k t+1}^{s}}{\lambda_{k t}^{s}}\right)=E_{t}\left(\frac{P_{k t+1}^{Y}}{P_{k t}^{Y}}\right)\left(\frac{1}{1+i_{t}^{g}}+\gamma_{b} \kappa P_{k t}^{N}\left(\kappa \frac{B_{k k t}^{g, S}}{B_{k k t}^{g, L, H}}-1\right)\right)
$$

FOC w.r.t. domestic long-term government bonds:

$$
\beta E_{t}\left(\frac{\lambda_{k t+1}^{s}}{\lambda_{k t}^{s}}\right)=E_{t}\left(\frac{P_{k t}^{N}}{\delta_{b} P_{k t+1}^{N}+c} \frac{P_{k t+1}^{Y}}{P_{k t}^{Y}}\right)\left(1+\frac{\gamma_{b}}{2}\left(\kappa \frac{B_{k t}^{g, S}}{B_{k k t}^{g, L, H}}-1\right)^{2}-\gamma_{b} \kappa\left(\kappa \frac{B_{k k t}^{g, S}}{B_{k k t}^{g, L, H}}-1\right) \frac{B_{k k t}^{g, S}}{B_{k k t}^{g, L, H}}\right)
$$

${ }^{23}$ See subsection A.1.3 for the labour supply condition. 
FOC w.r.t. RoW government bonds:

$$
\beta E_{t}\left[\frac{\lambda_{k t+1}^{S}}{\lambda_{k t}^{S}} \frac{\left(1+i_{R o W k t}^{g}\right) \frac{e_{R o W k t+1}}{e_{R o W k t}}-\varepsilon_{R o W k t}^{B}-\left(\alpha_{R o W k}^{b 0}+\alpha_{R o W k}^{b 1} \frac{e_{R o W k t} B_{R o W k t}^{g}}{P_{k}^{Y} Y_{k}}\right)}{1+\pi_{k t+1}^{C, v a t}}\right]=1
$$

where $\varepsilon_{\text {RoWkt }}^{B}$ is the risk premium on RoW bonds.

FOC w.r.t. domestic stocks:

$$
\beta E_{t}\left[\frac{\lambda_{k t+1}^{S}}{\lambda_{k t}^{S}} \frac{\left(1+i_{k t+1}^{S}\right)-\varepsilon_{k t}^{S}-\alpha_{k k}^{s 0}}{1+\pi_{t+1}^{C, v a t}}\right]=1
$$

where $\varepsilon_{k t}^{S}$ is the risk premium on stocks. The above optimality conditions are similar to a textbook Euler equation, but incorporate asset-specific risk premia, which depend on an exogenous shock $\varepsilon_{k t}^{A}$ as well as the size of the asset holdings as a share of GDP. Taking into account the Euler equation for the risk-free bond and approximating, they simplify to the familiar expressions:

$$
\begin{gathered}
i_{k t}^{g}=i_{k t}^{r f}+\text { rprem }_{k t}^{g} \\
E_{t}\left[\frac{e_{R o W k t+1}}{e_{\text {RoWkt }}}\right] i_{\text {RoWkt }}^{g}=i_{k t}^{r f}+\text { rprem }_{\text {RoWkt }}^{g} \\
i_{k t}^{s}=i_{k t}^{r f}+\text { rprem }_{k t}^{s}
\end{gathered}
$$

In the equations above, rprem $_{k t}^{g}$ is the risk premium on domestic government bonds. Similarly, rprem $_{\text {RoWkt }}^{g}$ is the risk premium on domestic government bonds sold abroad (to RoW). This feature of the model, hence, helps capture international spillovers that occur via the financial market channel. Finally, rprem $_{k t}^{s}$ is a crucial risk premium on domestic shares. It is introduced to capture in a stylised manner financial frictions that are commonly believed to have contributed to the first phase of the financial crisis and may have contributed to its second phase; see also subsection A.2.2, below. 


\section{A.1.2. Liquidity-constrained household}

The liquidity-constrained household consumes her disposable after-tax wage and transfer income in each period of time ("hand-to-mouth"). The period t budget constraint of the liquidityconstrained household is:

$$
\left(1+\tau_{k}^{C}\right) P_{k t}^{C} C_{j k t}^{c}=\left(1-\tau_{k}{ }^{N}\right) W_{k t} N_{k t}^{c}+T_{k t}^{c}-\operatorname{tax}^{c}{ }_{j k t} .
$$

The instantaneous utility function for liquidity-constrained households, $u^{c}(\cdot)$, is defined as:

$$
u^{c}\left(C_{j k t}^{c}, N_{j k t}^{c}\right)=\frac{1}{1-\theta}\left(C_{j k t}^{c}-h C_{k t-1}^{c}\right)^{1-\theta}-\left(C_{k t}^{c}\right)^{1-\theta} \frac{\omega^{N} \exp \left(u_{k t}^{U}\right)}{1+\theta^{N}}\left(N_{j k t}^{c}-h_{N} N_{k t-1}^{c}\right)^{1+\theta^{N}}
$$

with $C_{k t}^{c}=\int C_{j k t}^{c}$.

\section{A.1.3. Labour supply}

Trade unions are maximising a joint utility function for each type of labour. It is assumed that types of labour are distributed equally over Ricardian and liquidity-constrained households with their respective population weights. The wage rule is obtained by equating a weighted average of the marginal utility of leisure to a weighted average of the marginal utility of consumption times the real wage adjusted for a wage mark-up. Nominal rigidity in wage setting is introduced in the form of adjustment costs for changing wages. The wage adjustment costs are borne by the household. Real wage rigidity is also allowed, given the following optimality condition:

$$
\begin{aligned}
& \left(\left(1+\mu_{t}^{w}\right) \frac{\omega^{s} V_{1-l, j k t}^{s}+\left(1-\omega^{s}\right) V_{1-l, j k t}^{c}}{\omega^{s} U_{c, j k t}^{s}+\left(1-\omega^{s}\right) U_{c, j k t}^{c}}\left(1+\tau_{k}^{C}\right) p_{k t}^{C}\right)^{1-\gamma^{w r}}\left(\left(1-\tau_{k}^{N}\right) \frac{W_{k t-1}}{P_{k t-1}^{Y}}\right)^{\gamma^{w r}}=\left(1-\tau_{k}^{N}\right) \frac{W_{k t}}{P_{k t}^{Y}}+ \\
& \gamma^{w}\left(\pi_{t}^{w}-\left(1-s f^{w}\right) \pi_{t-1}^{w}\right)\left(1+\pi_{t}^{w}\right)-\gamma^{w} \frac{L_{t+1}}{L_{t}} \frac{1+\pi_{t+1}^{y}}{1+i_{t+1}^{s d}}\left(\pi_{t+1}^{w}-\left(1-s f^{w}\right) \pi_{t}^{w}\right)\left(1+\pi_{t+1}^{w}\right)
\end{aligned}
$$

where $\mu_{t}^{w}$ is the wage mark-up, $\gamma^{w r}$ is the degree of real wage rigidity, $\gamma^{w}$ is the degree of nominal wage rigidity and $s f^{w}$ is the degree of forward-lookingness in the labour supply equation. $V_{N, j k t}^{x}$, for $\mathrm{x}=\mathrm{s}, \mathrm{c}$, is the marginal disutility of labour, defined as:

$$
V_{N, j k t}^{x}=\omega^{N} \exp \left(u_{k t}^{U}\right) C_{k t}^{1-\theta}\left(N_{j k t}^{x}-h_{N} N_{k t-1}^{x}\right)^{\theta^{N}}
$$




\section{A.2. EA production sector}

\section{A.2.1. Total output demand}

Total output $O_{k t}$ is produced by perfectly competitive firms by combining value added, $Y_{k t}$, with energy input, $O i l_{k t}$, using the following CES production function:

$$
O_{k t}=\left[\left(1-s^{O i l}\right)^{\frac{1}{\sigma^{o}}}\left(Y_{k t}\right)^{\frac{\sigma^{o}-1}{\sigma^{o}}}+\left(s^{O i l}\right)^{\frac{1}{\sigma^{o}}}\left(O I L_{k t}\right)^{\frac{\sigma^{o}-1}{\sigma^{o}}}\right]^{\frac{\sigma^{o}}{\sigma^{o}-1}}
$$

where $s^{\text {oil }}$ is the energy input share in total output and elasticity $\sigma^{o}$ is inversely related to the steady-state output price gross mark-up. It follows that the demand for $Y_{k t}$ and $O I L_{k t}$ by total output producers is, respectively:

$$
\begin{gathered}
Y_{k t}=\left(1-s^{O i l}\right)\left(\frac{P_{k t}^{Y}}{P_{k t}^{O}}\right)^{-\sigma^{o}} O_{k t} \\
O I L_{k t}=s^{O i l}\left(\frac{P_{k t}^{O i l}}{P_{k t}^{O}}\right)^{-\sigma^{o}} O_{k t}
\end{gathered}
$$

where $P_{k t}^{Y}$ and $P_{k t}^{O i l}$ are price deflators associated with $Y_{k t}$ and $O i l_{k t}$, respectively, and the total output deflator $P_{k t}^{O}$ is such that:

$$
P_{k t}^{O}=\left[\left(1-s^{O i l}\right)\left(P_{k t}^{Y}\right)^{1-\sigma^{o}}+s^{o i l}\left(P_{k t}^{O i l}\right)^{1-\sigma^{o}}\right]^{\frac{1}{1-\sigma^{o}}}
$$

\section{A.2.2. Differentiated goods supply}

Each firm $i \in[0 ; 1]$ produces a variety of the domestic good which is an imperfect substitute for varieties produced by other firms. Because of imperfect substitutability, firms are monopolistically competitive in the goods market and face a downward-sloping demand function for goods. Domestic final good producers then combine the different varieties into a homogenous good and sell them to domestic final demand goods producers and exporters.

Differentiated goods are produced using total capital $K_{i k t-1}^{t o t}$ and labour $N_{i k t}$ which are combined in a Cobb-Douglas production function:

$$
Y_{i k t}=\left(A_{k t}^{Y} N_{i k t}\right)^{\alpha}\left(c u_{i k t} K_{i k t-1}^{t o t}\right)^{1-\alpha}
$$


where $A_{k t}^{Y}$ is a labour-augmenting productivity shock common to all firms in the differentiated goods sector and $c u_{i k t}$ is a firm-specific level of capital utilisation. Total Factor Productivity, $T F P_{k t}$, can therefore be defined as:

$T F P_{k t}=\left(A_{k t}^{Y}\right)^{\alpha}$.

We allow for three types of shocks related to the technology: a temporary shock $\varepsilon_{k t}^{A Y}$, which accounts for temporary deviations of $A_{k t}^{Y}$ from its trend, $\bar{A}_{k t}^{Y}$, and two shocks related to the trend components themselves:

$$
\begin{gathered}
\log \left(A_{k t}^{Y}\right)-\log \left(\bar{A}_{k t}^{Y}\right)=\varepsilon_{k t}^{A Y} \\
\log \left(\bar{A}_{k t}^{Y}\right)-\log \left(\bar{A}_{k t-1}^{Y}\right)=g_{k t}^{\overline{A Y}}+\varepsilon_{k t}^{L \overline{A Y}} \\
g_{k t}^{\overline{A Y}}=\rho^{\overline{A Y}} g_{k t-1}^{\overline{A Y}}+\varepsilon_{k t}^{G \overline{A Y}}+\left(1-\rho^{\overline{A Y}}\right) g^{\overline{A Y}}
\end{gathered}
$$

with $g^{\overline{A Y}}$ being the long-run technology growth.

Total capital is a sum of private installed capital, $K_{i k t}$, and public capital, $K_{i k t}^{g}$ :

$$
K_{i k t}^{t o t}=K_{i k t}+K_{i k t}^{g}
$$

The producers maximise the value of the firm, $V_{k t}$, equal to a discounted stream of future dividends, $V_{k t}=d_{k t}+E_{t}\left[s d f_{k t+1} V_{k t+1}\right]$, with the stochastic discount factor

$$
s d f_{k t}=\left(1+i_{k t}^{s d}\right) /\left(1+\pi_{k t}^{C, v a t}\right) \approx\left(1+i_{k t-1}^{r f}+\operatorname{rprem}_{k t-1}^{s}\right) /\left(1+\pi_{k t}^{C, v a t}\right)
$$

which depends directly on the investment risk premium, $\operatorname{rprem}_{k t-1}^{s}$. The dividends are defined as:

$$
d_{i k t}=\left(1-\tau_{k}^{K}\right)\left(\frac{P_{i k t}^{Y}}{P_{k t}^{Y}} Y_{i k t}-\frac{W_{k t}}{P_{k t}^{Y}} N_{i k t}\right)+\tau_{k}^{K} \delta \frac{P_{k t}^{I}}{P_{k t}^{Y}} K_{i k t-1}-\frac{P_{k t}^{I}}{P_{k t}^{Y}} I_{i k t}-a d j_{i k t}
$$

where $I_{i k t}$ is physical investment, $P_{k t}^{I}$ is investment price, $\tau_{k}^{K}$ is the profit tax, $\delta$ is the capital depreciation rate and $a d j_{i k t}$ are adjustment costs associated with price $P_{i k t}^{Y}$ and labour input $N_{i k t}$ adjustment or moving capacity utilisation $c u_{i k t}$ and investment $I_{i k t}$ away from their optimal level:

$$
\operatorname{adj}_{i k t}=\operatorname{adj}\left(P_{i k t}^{Y}\right)+\operatorname{adj}\left(N_{i k t}\right)+\operatorname{adj}\left(c u_{i k t}\right)+\operatorname{adj}\left(I_{i k t}\right)
$$


where

$$
\begin{gathered}
\operatorname{adj}\left(P_{i k t}^{Y}\right)=\frac{\gamma^{p}}{2} Y_{k t}\left(\frac{P_{i k t}^{Y}}{P_{i k t-1}^{Y}}-1\right)^{2} \\
\operatorname{adj}\left(N_{i k t}\right)=\frac{\gamma^{n}}{2} Y_{k t}\left(\frac{N_{i k t}}{N_{i k t-1}}-1\right)^{2} \\
\operatorname{adj}\left(c u_{i k t}\right)=\frac{P_{k t}^{I}}{P_{k t}^{Y}} K_{i k t-1}\left(\gamma^{u, 1}\left(c u_{i k t}-1\right)+\frac{\gamma^{u, 2}}{2}\left(c u_{i k t}-1\right)^{2}\right) \\
\operatorname{adj}\left(I_{i k t}\right)=\frac{P_{k t}^{I}}{P_{k t}^{Y}}\left(\frac{\gamma^{I, 1}}{2} K_{k t-1}\left(\frac{I_{i k t}}{K_{k t-1}}-\delta\right)^{2}+\frac{\gamma^{I, 2}}{2} \frac{\left(I_{i k t}-I_{i k t-1}\right)^{2}}{K_{k t-1}}\right)
\end{gathered}
$$

The maximisation is subject to production function, standard capital accumulation equation:

$$
K_{i k t}=(1-\delta) K_{i k t-1}+I_{i k t}
$$

and the usual demand condition, which inversely links demand for variety $i$ goods and the price of the variety:

$$
Y_{i k t}=\left(\frac{P_{i k t}^{Y}}{P_{k t}^{Y}}\right)^{-\sigma^{y}} Y_{k t}
$$

Let $a d j_{X, i k t}$ for $X=P^{Y}, N, c u, I$ denote additional dynamic terms due to the existence of adjustment costs. Let us also define $g_{k t}^{X}:=\frac{X_{k t}-X_{k t-1}}{X_{k t-1}}$ the net growth rate of variable $X=N, Y, I, C, \ldots$ and $\pi_{k t}^{X}:=\frac{\Delta P_{k t}^{X}}{P_{k t-1}^{X}}$ the inflation rate of a price deflator associated with variable $X=N, Y, I, C, \ldots$ The main optimality conditions of the differentiated goods producers are as follows.

The usual equality between the marginal product of labour and labour cost holds, with a wedge driven by the labour adjustment costs:

$$
\mu_{k t}^{y} \alpha \frac{Y_{k t}}{N_{k t}}-a d j_{N, i k t}=\left(1-\tau^{k}\right) \frac{W_{k t}}{P_{k t}^{Y}}
$$

with $\mu_{k t}^{y}$ being inversely related to the price mark-up. The capital optimality condition reflects the usual dynamic trade-off faced by the firm:

$$
\frac{1+\pi_{k t+1}^{y}}{1+i_{k t+1}^{s d}} \frac{P_{k t+1}^{I} / P_{k t+1}^{Y}}{P_{k t}^{I} / P_{k t}^{Y}}\left(\mu_{k t+1}^{y}(1-\alpha) \frac{P_{k t+1}^{Y} Y_{i k t+1}}{P_{k t+1}^{I} K_{i k t}^{t o t}}+\tau^{k} \delta-a d j_{k t}^{c u} / K_{i k t}+(1-\delta) Q_{k t+1}\right)=Q_{k t}
$$

where $Q_{k t}$ has the usual Tobin's interpretation. 
FOC w.r.t. investment implies that Tobin's Q varies due to the existence of investment adjustment costs:

$$
Q_{k t}=1+a d j_{I, i k t}
$$

Firms adjust their capacity utilisation depending on the conditions on the market via the optimality condition:

$$
\frac{\mu_{k t}^{y}}{P_{k t}^{I} / P_{k t}^{Y}}(1-\alpha) \frac{Y_{k t}}{c u_{k t}}=a d j_{c u, i k t}
$$

Finally, the FOC w.r.t. differentiated output price pins down the price mark-up:

$$
\frac{\sigma^{y}}{\left(\sigma^{y}-1\right)} \mu_{k t}^{y}=\left(1-\tau^{k}\right)+\frac{a d j_{P^{Y}, i k t}}{\left(\sigma^{y}-1\right)}+\varepsilon_{k t}^{\mu}
$$

with $\varepsilon_{k t}^{\mu}$ being the mark-up shock. The latter equation, combined with the FOC w.r.t. labour implies the Phillips curve of the familiar form.

\section{A.3. Trade}

\section{A.3.1. Import sector}

\section{Aggregate demand components}

The final aggregate demand component goods $C_{k t}$ (private consumption good), $I_{k t}$, (private investment good) $G_{k t}$ (government consumption good) and $I_{k t}^{G}$ (government investment good) are produced by perfectly competitive firms by combining domestic output, $O_{k t}^{Z}$ with imported goods $M_{k t}^{Z}, Z=C, I, G, I^{G}$, using the following CES production function:

$$
Z_{k t}=A_{k t}^{p^{z}}\left[\left(1-\varepsilon_{k t}^{M} S^{M, Z}\right)^{\frac{1}{\sigma^{z}}}\left(O_{k t}^{Z}\right)^{\frac{\sigma^{z}-1}{\sigma^{Z}}}+\left(\varepsilon_{k t}^{M} S^{M, Z}\right)^{\frac{1}{\sigma^{Z}}}\left(M_{k t}^{Z}\right)^{\frac{\sigma^{z}-1}{\sigma^{Z}}}\right]^{\frac{\sigma^{Z}}{\sigma^{z}-1}}
$$

with $A_{k t}^{p^{z}}$ a shock to productivity in the sector producing goods $Z$ and $\varepsilon_{k t}^{M}$ is a shock to the share $s^{M, Z}$ of imports in domestic demand components. We assume that the log difference of the specific productivities, $A_{k t}^{p^{z}}$, is an $\operatorname{AR}(1), \varepsilon_{k t}^{p^{z}}$ with mean $g^{p^{z}}$. It follows that the demand for the domestic and foreign part of demand aggregates is: 


$$
\begin{gathered}
O_{k t}^{Z}=\left(A_{k t}^{p^{z}}\right)^{\sigma^{Z}-1}\left(1-\varepsilon_{k t}^{M} s^{M, Z}\right)\left(\frac{P_{k t}^{O}}{P_{k t}^{Z}}\right)^{-\sigma^{Z}} Z_{k t} \\
M_{k t}^{Z}=\left(A_{k t}^{p^{Z}}\right)^{\sigma^{Z}-1} \varepsilon_{k t}^{M} s^{M, Z}\left(\frac{P_{k t}^{M}}{P_{k t}^{Z}}\right)^{-\sigma^{Z}} Z_{k t}
\end{gathered}
$$

where $P_{k t}^{Z}$ are price deflators associated with $Z_{k t}$; they satisfy:

$$
P_{k t}^{Z}=\left(A_{k t}^{p^{z}}\right)^{-1}\left[\left(1-\varepsilon_{k t}^{M} s^{M, Z}\right)\left(P_{k t}^{O}\right)^{1-\sigma^{Z}}+\varepsilon_{k t}^{M} s^{M, Z}\left(P_{k t}^{M}\right)^{1-\sigma^{Z}}\right]^{\frac{1}{1-\sigma^{Z}}}
$$

\section{Economy-specific final imports demand}

Final imported goods are produced by perfectly competitive firms combining economy-specific homogenous imports goods, $M_{l k t}$, using CES production function:

$$
M_{k t}=\left(\sum_{l}\left(s_{l k t}^{M}\right)^{\frac{1}{\sigma^{F M}}}\left(M_{l k t}\right)^{\frac{\sigma^{F M}-1}{\sigma^{F M}}}\right)^{\frac{\sigma^{F M}}{\sigma^{F M}-1}}
$$

where $\sigma^{F M}$ is the price elasticity of demand for country $l$ 's goods and $\sum_{l} s_{l k t}^{M}=1$ are import shares. The demand for goods from country $l$ is then:

$$
M_{l k t}=s_{l k t}^{M}\left(\frac{P_{l k t}^{M}}{P_{k t}^{M}}\right)^{-\sigma^{F M}} M_{k t}
$$

while the imports price:

$$
P_{k t}^{M}=\left(\sum_{l} s_{l k t}^{M}\left(P_{l k t}^{M}\right)^{1-\sigma^{F M}}\right)^{\frac{1}{1-\sigma^{F M}}}
$$

with $P_{l k t}^{M}$ being the country-specific imports good prices.

\section{Supply of economy- and sector-specific imports}

The homogenous goods from country $l$ are assembled by monopolistically competitive firms from economy- and sector-specific goods using a linear production function and subject to adjustment costs. All products from country $l$ are initially purchased at export price $P_{l t}^{X}$ of this country. Firms then maximise a discounted stream of profits, $d i v_{k t}^{I M}$, such that :

$$
d i v_{i l k t}^{I M}=\frac{P_{i l k t}^{M}}{P_{k t}^{Y}} M_{i l k t}-e_{l k t} \frac{P_{l t}^{X}}{P_{k t}^{Y}} M_{i l k t}-\operatorname{adj} j_{i l k t}^{P M}
$$


where $a d j_{i l k t}^{P M}$ are the adjustment costs that producers face when choosing the bilateral import price. $^{24}$ The maximisation is subject to the usual inversely sloping demand equation. These assumptions result in a simple expression for price $P_{l k t}^{M}$ of homogenous goods from country $l$ :

$$
P_{l k t}^{M}=e_{l k t} P_{l t}^{X}-a d j_{M, i l k t}^{P M}
$$

where $\operatorname{adj}_{M, i l k t}^{P M}$ are additional dynamic terms due to costs of adjustment.

\section{A.3.2. Export sector}

The exporting firms are supposed to be competitive and set their prices equal to the output price, up to a shock, $\varepsilon_{k t}^{X}$ :

$$
P_{k t}^{X}=\varepsilon_{k t}^{X} P_{k t}^{O}
$$

\section{A.4. Monetary policy}

The operating profit of the central bank equals the sum of base money issuance and interest income minus the current expenditure on buying long-term bonds, where the latter equals the change of the value of long-term bonds on the central bank's balance sheet:

$$
P R_{k t}^{C B}=\Delta M_{k t}+c B_{j k k, t-1}^{g, L, C B}-\left(P_{k t}^{N} B_{j k k t}^{g, L, C B}-\delta_{b} P_{k t}^{N} B_{j k k, t-1}^{g, L, C B}\right)
$$

Under the central bank's budget constraint, purchases of long-term government bonds can be financed either by increasing liquidity (money issuance), or by reducing the central bank's operating profit. ${ }^{25}$ Purchases of long-term bonds by the central bank are modelled as an exogenous path that replicates the announced ECB programme in timing and size.

Monetary policy in "normal times" is modelled by a Taylor rule where the ECB sets the policy rate $i_{k t}$ in response to area-wide inflation and real GDP growth. The policy rate adjusts sluggishly to deviations of inflation and GDP growth from their respective target levels; it is also subject to random shocks:

$$
i_{k t}-\bar{\imath}=\rho^{i}\left(i_{k t-1}-\bar{\imath}\right)+\left(1-\rho^{i}\right)\left(\eta^{i \pi}\left(0.25\left(\sum_{r=0}^{3} \pi_{k t-r}^{c, v a t}\right)-\bar{\pi}^{c, v a t}\right)+\eta^{i y}\left(\tilde{y}_{k t}\right)\right)+u_{k t}^{i n o m}
$$

${ }^{24} a d j_{i l k t}^{P M}=\frac{\gamma^{p M}}{2} \frac{P_{l k t}^{M}}{P_{k t}^{Y}} M_{l k t-1}\left(\frac{P_{\text {llkt }}^{M}}{P_{\text {llkt }-1}^{M}}-1\right)^{2}$

${ }^{25}$ A third option, in general, is for the central bank to sell other assets from its portfolio to sterilise the impact of its intervention on the central bank balance sheet. We discard this possibility in our model by limiting central bank assets to long-term government bonds. 
where $i=r+\pi^{Y}$ is the steady-state nominal interest rate, equal to the sum of the steady-state real interest rate and GDP inflation, $\tilde{y}_{k t}=\log \left(Y_{k t}\right)-\bar{y}_{k t}$ is the output gap with $\bar{y}_{t}$ as $(\log )$ potential output. It is assumed that the risk-free rate is equal to the policy rate: $i_{k t}^{s d} \equiv i_{k t}$.

\section{A.5. Fiscal policy}

Government expenditure and receipts can deviate temporarily from their long-run levels in systematic response to budgetary or business-cycle conditions and in response to idiosyncratic shocks. Concerning government consumption and government investment, we specify the following autoregressive equations:

$$
\begin{gathered}
\frac{G_{k t}}{\bar{Y}_{k t} A_{k t}^{P G}}-\bar{G}=\rho^{G}\left(\frac{G_{k t-1}}{\bar{Y}_{k t} A_{k t}^{P G}}-\bar{G}\right)+u_{k t}^{G} \\
\frac{I_{k t}^{G}}{\bar{Y}_{k t} A_{k t}^{P I}}-\bar{I}^{G}=\rho^{I G}\left(\frac{I_{k t-1}^{G}}{\bar{Y}_{k t} A_{k t}^{P I}}-\bar{I}^{G}\right)+u_{k t}^{I G} \\
\frac{T_{k t}}{\bar{P}_{k t}^{Y} Y_{k t}}-\bar{T}=\rho^{T}\left(\frac{T_{k t-1}}{\bar{P}_{k t}^{Y} \bar{Y}_{k t}}-\bar{T}\right)+\eta^{D E F, T}\left(\frac{\Delta B_{k t}^{g t o t}}{P_{k t}^{Y} Y_{k t}}-d e f^{T}\right)+\eta^{B, T}\left(\frac{B_{k t}^{g t o t}}{P_{k t}^{Y} Y_{k t}}-\bar{B}_{k}^{G}\right)+u_{k t}^{T}
\end{gathered}
$$

with $B_{k t}^{g t o t}$ total nominal government debt. Government transfers react to the level of government debt and the government deficit relative to the associated debt and deficit targets $\bar{B}_{k}^{G}$ and $\operatorname{def}^{T}$.

The government budget constraint is

$$
\frac{B_{j k k t}^{g, S}}{\left(1+i_{k t}\right) P_{k t}^{Y}}+\frac{P_{k t}^{N}}{P_{k t}^{Y}} B_{j k k t}^{g, L}=\frac{B_{k t-1}^{g, S}}{P_{k t}^{Y}}+\frac{\left(\delta_{b} P_{k t}^{N}+c\right) B_{j k k, t-1}^{g, L}}{P_{k t}^{Y}}-\frac{P R_{k t}^{C B}}{P_{k t}^{Y}}-R_{k t}^{G}+P_{k t}^{G} G_{k t}+P_{k t}^{I G} I_{k t}^{G}+T_{k t}
$$

where government (nominal) revenue:

$$
R_{k t}^{G}=\tau_{k}^{K}\left(P_{k t}^{Y} Y_{k t}-W_{k t} N_{k t}-P_{k t}^{I} \delta_{k} K_{k t-1}\right)+\tau^{N} W_{k t} N_{k t}+\tau^{C} P_{k t}^{C} C_{k t}+t a x_{k t}
$$

consists of taxes on consumption, labour and corporate income, as well as lump-sum tax.

Finally, the accumulation equation for government capital is:

$$
K_{k t}^{G}=\left(1-\delta^{G}\right) K_{k t-1}^{G}+I_{k t}^{G}
$$

\section{A.6. The RoW block}

The model of the RoW economy (subscript k=RoW) is a simplified structure with fewer shocks. Specifically, the RoW consists of a budget constraint for the representative household, demand functions for domestic and imported goods (derived from CES consumption good aggregators), a production technology that uses labour as the sole factor input, and a New Keynesian Phillips curve. The RoW block abstracts from capital accumulation. There are shocks to labour productiv- 
ity, price mark-ups, the subjective discount rate and the relative preference for domestic vs. imported goods, as well as monetary policy shocks in the RoW.

More specifically, the budget constraint for the RoW representative household is:

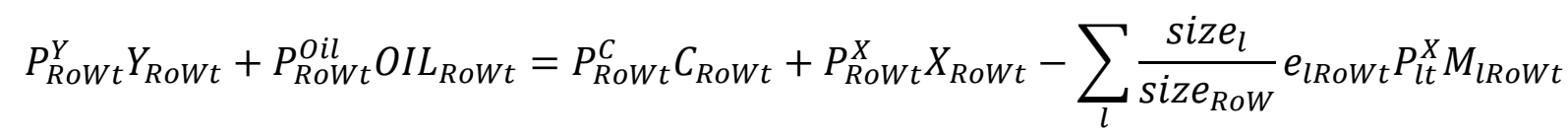

where $X_{\text {RoWt }}$ are non-oil exports by the RoW, and the intertemporal equation for aggregate demand derived from the FOC for consumption:

$$
\beta_{t} \frac{\lambda_{\text {RoWt+1 }}}{\lambda_{\text {RoWt }}} \frac{1+i_{\text {RoWt }}}{1+\pi_{\text {RoWt+1 }}^{C}}=1
$$

with $\beta_{t}=\beta \exp \left(\varepsilon_{R o W t}^{C}\right),\left(C_{R o W t}-h C_{R o W t-1}\right)^{-\theta}=\lambda_{R o W t}$ and $\varepsilon_{R o W t}^{C}$ as the RoW demand shock. Note that $i_{\text {RoWt }} \equiv i_{\text {RoWkt }}^{g}$

As for the EA, final aggregate demand $C_{R o W t}$ (in the absence of investment and government spending in the RoW block) is a combination of domestic output, $Y_{\text {RoWt }}$ and imported goods, $M_{R o W t}$, using the following CES function:

$$
C_{\text {RoWt }}=A_{\text {RoWt }}^{p}\left[\left(1-\varepsilon_{\text {RoWt }}^{M} S^{M}\right)^{\frac{1}{\sigma}}\left(Y_{R o W t}^{C}\right)^{\frac{\sigma-1}{\sigma}}+\left(\varepsilon_{\text {RoWt }}^{M} S^{M}\right)^{\frac{1}{\sigma}}\left(M_{R o W t}^{C}\right)^{\frac{\sigma-1}{\sigma}}\right]^{\frac{\sigma}{\sigma-1}}
$$

which gives the demand for the domestic and foreign goods in RoW demand:

$$
\begin{gathered}
Y_{\text {RoWt }}^{C}=\left(A_{\text {RoWt }}^{p}\right)^{\sigma-1}\left(1-\varepsilon_{\text {RoWt }}^{M} S^{M}\right)\left(\frac{P_{\text {RoWt }}^{Y}}{P_{\text {RoWt }}^{C}}\right)^{-\sigma} C_{\text {RoWt }} \\
M_{\text {RoWt }}^{C}=\left(A_{\text {RoWt }}^{p}\right)^{\sigma-1} \varepsilon_{\text {RoWt }}^{M} S^{M}\left(\frac{P_{\text {RoWt }}^{M}}{P_{\text {RoWt }}^{C}}\right)^{-\sigma} C_{\text {RoWt }}
\end{gathered}
$$

where the consumer price deflator $P_{\text {Rowt }}^{C}$ satisfies:

$$
P_{\text {RoWt }}^{C}=\left(A_{\text {RoWt }}^{p}\right)^{-1}\left[\left(1-\varepsilon_{\text {RoWt }}^{M} S^{M}\right)\left(P_{R o W t}^{Y}\right)^{1-\sigma}+\varepsilon_{R o W t}^{M} S^{M}\left(P_{R o W t}^{M}\right)^{1-\sigma}\right]^{\frac{1}{1-\sigma}}
$$

The RoW non-oil output is produced with the technology:

$$
Y_{\text {RoWt }}=A_{\text {RoWt }}^{Y} N_{\text {RoWt }}
$$

Price-setting for RoW non-oil output follows a New Keynesian Phillips curve:

$$
\begin{aligned}
\pi_{\text {RoWt }}^{Y}-\bar{\pi}_{\text {RoW }}^{Y} & =\beta \frac{\lambda_{\text {RoWt+1 }}}{\lambda_{\text {RoWt }}}\left(\operatorname{sfp}\left(E_{t} \pi_{\text {RoWt }+1}^{Y}-\bar{\pi}_{\text {RoW }}^{Y}\right)+(1-s f p)\left(\pi_{\text {RoWt-1 }}^{Y}-\bar{\pi}_{\text {RoW }}^{Y}\right)\right) \\
& +\varphi_{\text {RoW }}^{Y} \ln \left(Y_{\text {RoWt }}-\bar{Y}_{\text {RoW }}\right)+\varepsilon_{\text {RoWt }}^{Y}
\end{aligned}
$$

Monetary policy in the RoW follows the Taylor rule:

$$
i_{\text {RoWt }}-\bar{\imath}=\rho^{i}\left(i_{\text {RoWt }-1}-\bar{l}\right)+\left(1-\rho^{i}\right)\left(\eta^{i \pi}\left(\pi_{\text {RoWt }}^{Y}-\bar{\pi}_{\text {RoW }}^{Y}\right)+\eta^{i y} \tilde{y}_{\text {RoWt }}\right)+\varepsilon_{\text {RoWt }}^{\text {inom }}
$$


where $\tilde{y}_{\text {RoWt }}$ is the deviation of actual output from trend output.

The RoW net foreign asset (NFA) position is equal to minus the EA NFA position.

Finally, oil is assumed to be fully imported from the RoW and the oil price is assumed as follows:

$$
P_{\text {RoWt }}^{\text {Oil }}=\frac{\bar{P}^{Y}}{A_{\text {ROWt }}^{p^{\text {oil }} e_{\text {RoW,US }}}}
$$

where $A_{R O W t}^{p^{o i l}}$ is oil-specific productivity and oil is priced in USD.

Total nominal exports are defined as:

$$
P_{\text {RoWt }}^{X} X_{\text {RoWt }}=\sum_{l} P_{l \text { RoWt }}^{X} M_{\text {RoWlt }}
$$

with the bilateral export price being defined as the domestic price subject to a bilateral price shock:

$$
P_{\text {lRoWt }}^{X}=\exp \left(\varepsilon_{\text {lRoWt }}^{P X}\right) P_{\text {RoWt }}^{Y}
$$

\section{A.7 Closing the economy}

Market clearing requires that:

$$
Y_{k t} P_{k t}^{Y}+d i v_{k t}^{M} P_{k t}^{Y}=P_{k t}^{C} C_{k t}+P_{k t}^{I} I_{k t}+P_{k t}^{I G} I G_{k t}+T B_{k t}
$$

Export is a sum of imports from the domestic economy by other countries: $X_{k t}=\sum_{l} M_{k l t}$ where $M_{k l t}$ stands for imports from the domestic economy to economy $l$. The total imports are defined as:

$$
P_{k t}^{M t o t} M_{k t}^{t o t}=P_{k t}^{M} M_{k t}+P_{k t}^{o i l} O I L_{k t}
$$

where non-oil imports

$$
\begin{gathered}
P_{k t}^{M} M_{k t}=P_{k t}^{M}\left(M_{k t}^{C}+M_{k t}^{I}+M_{k t}^{G}+M_{k t}^{I G}\right) \\
e_{R o W k, t} B_{k, t}^{w}=+\left(1+i_{t-1}^{b w}\right) e_{R o W k, t} B_{k, t-1}^{w}+P_{k t}^{X} X_{k t}-\sum_{l} \frac{s i z e_{l}}{s i z e_{k}} e_{l k t} P_{l t}^{X} M_{l k t}-P_{k t}^{O i l} O I L_{k t} \\
+I T R_{k} \bar{P}_{k t}^{Y} Y_{k t}
\end{gathered}
$$

where $P_{k t}^{X} X_{k t}-\sum_{l} \frac{\text { size }_{l}}{\text { size }_{k}} e_{l k t} P_{l t}^{X} M_{l k t}-P_{k t}^{O i l} O I L_{k t}=T B_{k t}$ defines the trade balance, with domestic importers buying the imported good at the price $\mathrm{P}_{\mathrm{lt}}^{\mathrm{X}}$. We allow non-zero trade balance and include an international transfer, $I T R_{k}$, calibrated in order to satisfy zero NFA in equilibrium.

Finally, NFAs of each country sum to zero:

$$
\sum_{l} N F A_{l t} \operatorname{size}_{l}=0 .
$$

size $_{l}$ is the relative size of economy $l$. 


\section{B. Data}

\section{B.1. Data sources}

Data for the EA (quarterly national accounts, fiscal aggregates, quarterly interest and exchange rates) are taken from Eurostat. RoW series are constructed on the basis of the International Monetary Fund's (IMF's) International Financial Statistics (IFS) and World Economic Outlook (WEO) databases.

\section{B.2. Constructing of data series for RoW variables}

Series for GDP and prices in the RoW starting in 1999 are constructed on the basis of data for the following 59 countries: Albania, Algeria, Argentina, Armenia, Australia, Azerbaijan, Belarus, Brazil, Bulgaria, Canada, Chile, China, Colombia, Croatia, Czech Republic, Denmark, Egypt, Georgia, Hong Kong, Hungary, Iceland, India, Indonesia, Iran, Israel, Japan, Jordan, Korea, Lebanon, Libya, FYR Macedonia, Malaysia, Mexico, Moldova, Montenegro, Morocco, New Zealand, Nigeria, Norway, Philippines, Poland, Romania, Russia, Saudi Arabia, Serbia, Singapore, South Africa, Sweden, Switzerland, Syria, Taiwan, Thailand, Tunisia, Turkey, Ukraine, United Arab Emirates, United Kingdom, United States, and Venezuela. The RoW data are annual data from the IMF IFS and WEO databases.

\section{B.3. List of observables}

The estimation uses the following time series for the EA: GDP, GDP deflator, population, total employment, employment rate, employment in hours, participation rates, relative prices with respect to GDP deflator (VAT consumption, government consumption, private investment, export, and import), government investment price relative to private investment, nominal policy rate, and nominal shares of GDP (consumption, government consumption, investment, government investment, government interest payment, transfers, public debt, wage bill and exports). The list of observables also includes the oil price and the effective exchange rate of the EA. For the RoW we use data on population, GDP, GDP deflator and the nominal policy rate. The EA-specific QE observables are securities held for monetary policy purposes as proxy for long-term bond holdings by the ECB and the share of long-term debt in total government debt. Furthermore, we use current and three-month-ahead swap rates on 10-year government bonds to calculate the implied expected period-on-period return on long-term bonds. 


\section{Parameter Identification}

Figure C.1: Prior and posterior identification of GAMMAB
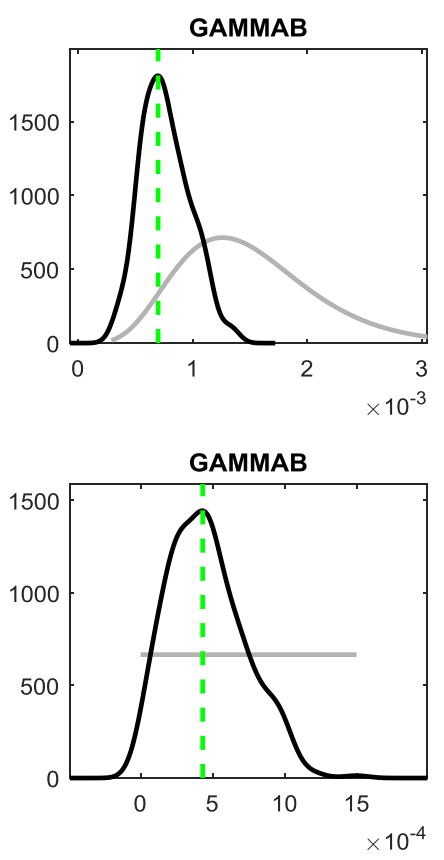

Figure C. 1 shows the posterior distributions of the estimated portfolio adjustment cost parameters $\left(\gamma_{b}\right)$ using an informative gamma prior (upper panel) and an uninformative uniform prior (lower panel). It depicts that both estimations provide a similar posterior mode, implying a wellidentified parameter. 


\section{Model Fit}

Figure D.1: Bayesian 1-step-ahead prediction
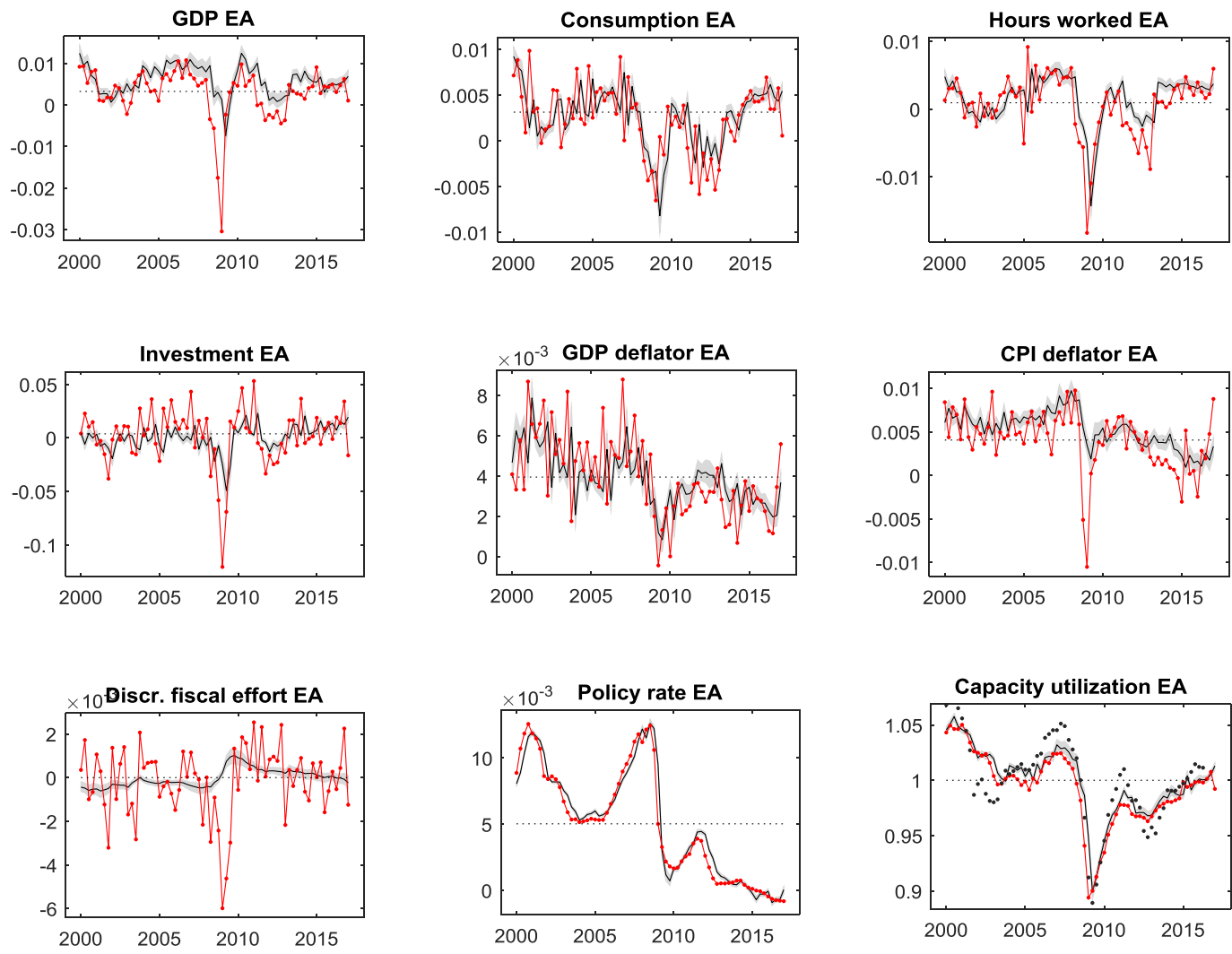

In order to assess the fit of the model, we can compare the estimates of endogenous variables with their observable counterparts. Figure D.1 shows the Bayesian one-step-ahead prediction for key observable variables. The red line indicates the observed series from $1999 \mathrm{q} 1$ to $2017 \mathrm{q} 1$. The black line depicts the model-consistent estimate of the one-step-ahead forecast of the endogenous variable calculated by the Kalman filter. The grey confidence bounds represent posterior parameter uncertainty. A specific indicator for the ability of our estimated model to replicate key features of EA business cycles is to focus on capacity utilisation. While capacity utilisation is not directly measurable in national account statistics, we use a "model-free" or reduced-form proxy that has been constructed to compare the model-based with the model-free estimate of capacity utilisation. The lower right panel in Figure D.1 plots the times series of capacity utilisation implied by the constructed proxy (black dotted line) and the model-implied one computed via Kalman filter. Even without directly observing capacity utilization, the two measures coincide and give additional credit to the plausibility of the estimated model to replicate key features of EA business cycles. 


\section{E. Historical Sequence of Regimes from 2013q1 to 2017q1}

Table E.1: Estimation of the historical sequence of occasionally binding regimes from $2013 q 1$ to $2017 q 1$ under alternative QE shock processes

\begin{tabular}{|c|c|c|c|c|}
\hline \multirow[b]{2}{*}{ Time } & \multicolumn{2}{|c|}{$A R(2)$} & \multicolumn{2}{|c|}{$A R(1)$} \\
\hline & $\begin{array}{r}\text { Regime } \\
\text { sequence }^{1}\end{array}$ & $\begin{array}{r}\text { Starting period } \\
\text { of regime }\end{array}$ & $\begin{array}{r}\text { Regime } \\
\text { sequence }^{1}\end{array}$ & $\begin{array}{r}\text { Starting period } \\
\text { of regime }\end{array}$ \\
\hline $2013 q 1$ & 0 & 1 & 0 & 1 \\
\hline $2013 q 2$ & 0 & 1 & 0 & 1 \\
\hline $2013 q 3$ & 0 & 1 & 0 & 1 \\
\hline $2013 q 4$ & 0 & 1 & 0 & 1 \\
\hline 2014q1 & 0 & 1 & 0 & 1 \\
\hline $2014 q 2$ & 0 & 1 & 0 & 1 \\
\hline $2014 q 3$ & 0 & 1 & 0 & 1 \\
\hline $2014 q 4$ & 10 & 14 & 10 & 14 \\
\hline $2015 q 1$ & 10 & 15 & 10 & 15 \\
\hline $2015 q 2$ & 10 & 13 & 10 & 13 \\
\hline $2015 q 3$ & 10 & 13 & 10 & 13 \\
\hline $2015 q 4$ & 10 & 14 & 10 & 13 \\
\hline $2016 q 1$ & 10 & 15 & 10 & 15 \\
\hline $2016 q 2$ & 10 & 13 & 10 & 13 \\
\hline $2016 q 3$ & 10 & 13 & 10 & 13 \\
\hline $2016 q 4$ & 10 & 12 & 10 & 13 \\
\hline 2017q1 & 0 & 1 & 0 & 1 \\
\hline
\end{tabular}

Notes: (First column) $0=$ unconstrained, $1=$ constrained. [1 0 ] indicates a constrained regime. (Second column) Periods for which the regime starts: [1 5] indicates a constrained regime for 4 periods.

Table E.1 provides a comparison of historical binding regimes from 2013q1 to 2017q1 under two alternative $\mathrm{QE}$ shock process estimations, namely $\mathrm{AR}(2)$ and $\mathrm{AR}(1)$. It suggests that monetary policy returns back to "normal times" in 2017q1 in both cases, although agents in 2016q4 anticipate two more quarters of binding constraint under an AR(1) process, which has been estimated as a very persistent and long-lasting process with a persistence parameter of 0.99 . The humpshaped pattern implied by an $\mathrm{AR}(2)$ corresponds to an anticipation of further asset purchases. It leads to a more frontloaded effect on output, implying stronger upward pressure on domestic prices and, therefore, an earlier tightening of monetary policy. 